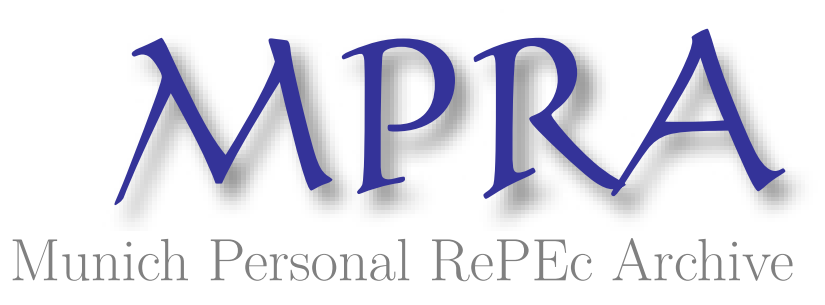

\title{
Examining the Ability of Core Inflation to Capture the Overall Trend of Total Inflation
}

Tierney, Heather L.R.

College of Charleston

August 2009

Online at https://mpra.ub.uni-muenchen.de/22409/

MPRA Paper No. 22409, posted 30 Apr 2010 02:09 UTC 


\title{
Examining the Ability of Core Inflation to Capture the Overall Trend of Total Inflation
} by

\author{
Heather L. R. Tierney ${ }^{*}$
}

February 2010

\begin{abstract}
This paper examines whether core inflation is able to predict the overall trend of total inflation using real-time data in a parametric and nonparametric framework. Specifically, two sample periods and five in-sample forecast horizons in two measures of inflation, which are the personal consumption expenditure and the consumer price index, are used in the exclusions-from core inflation persistence model. This paper finds that core inflation is only able to capture the overall trend of total inflation for the twelve-quarter in-sample forecast horizon using the consumer price index in both the parametric and nonparametric models in the longer sample period. The nonparametric model outperforms the parametric model for both data samples and for all five in-sample forecast horizons.
\end{abstract}

KEY WORDS: Inflation Persistence, Real-Time Data, Monetary Policy, Nonparametrics, In-Sample Forecasting

JEL Classification Codes: E52, C14 , C53

\footnotetext{
* Contact author: Heather L.R. Tierney, School of Business and Economics, College of Charleston, 5 Liberty Street, Charleston, SC 29424, email: hlrtierney@yahoo.com, phone: (843) 953-7070, fax: (843) 953-5697. I would like to thank in alphabetical order the following people for their gracious help that took various forms that ranged from guidance to comments: Richard Ashley, Yong Bao, Marcelle Chauvet, Dean Croushore, Daniel Henderson, James Morley, Peter C.B. Phillips, Zeynep Senyuz, Mark Watson, and Emre Yoldas, and last but not least, the participants of the $18^{\text {th }}$ Annual Meeting of the Midwest Econometrics Group (2008) and the $78^{\text {th }}$ Annual Meeting of the Southern Economics Association (2008).
} 


\section{Introduction}

The definition of core inflation varies by country with the U.S. definition of core inflation generally being total inflation minus the volatile components of food and energy, which is specifically examined in this paper. Generally, core inflation is thought of as a long-run concept, but core inflation can have implications in the shortand medium-run especially in regards to policy matters (Gagnon 2008). The primary intent of core inflation is to capture the underlying trend of total inflation by not reflecting the changes in relative prices or temporary supply shocks that could be eliminated rather rapidly. The implication of this primary intent is that core inflation should then have some predictive capability in regards to total future inflation at some forecast horizon that could include the relative short- and medium-run (Clark 2001).

The purpose of this paper is to investigate whether core inflation is able to predict the overall trend of total inflation, and if so, how fast, does this occur. Insample forecasting is used to see if the exclusions-from-core measures of inflation have an impact on total inflation. Suppose core inflation is able to capture the underlying trend of total inflation, this implies that core inflation is an unbiased predictor of total inflation and should be continued to be used in monetary policy (Silver 1997). In this paper, inflation persistence is examined through the use of the exclusions-from-core inflation persistence model over a five-period in-sample forecast horizon of one, two, four, eight, and twelve quarts using real-time data. This paper also examines the effect of data revisions for fifty vintages of real-time data in two sample periods. Two types of core and total inflation measures, Personal Consumption Expenditures (PCE) and the Consumer Price Index (CPI), are used to examine the effect that the exclusions-from-core has on total inflation.

The performance of PCE and CPI as an inflation measure is compared to see if the inflation measure has an effect on inflation persistence. Regarding PCE, the Federal Reserve currently uses the PCE to forecast core and total inflation since the PCE does not have as large of an upward bias as CPI due to the substitution effect. The PCE covers the whole consumption side of the economy as opposed to only the goods and services purchased by the typical urban consumer, which the CPI covers. The PCE is also subject to revision when additional source data becomes available, which enables a better break down between a change in real consumption and a change in consumer prices (Croushore 2007). Alternatively, as stated by Rich and Steindel (2005), since the price of capital goods purchased by firms is difficult to measure as are goods purchased by the government such as education, a consumer-based price index such as the CPI may be a better measure of inflation because production costs 
are passed along to the consumer as is government purchases through the form of taxation, which decreases consumers' purchasing ability. In addition, the CPI is also an inflation measure that is more familiar to the general public. Since it is not revised, the CPI might appear to be more reliable to the general public and thereby, better able to capture the general trend of inflation (Lafléche and Armour 2006). Hence, as one can see, a case for using either PCE or the CPI as a measure of inflation can easily be made.

Although this paper concerns the U.S. PCE and the U.S. CPI, much of the existing literature in this area has been done in regards to the Canadian CPI. Lafléche and Armour (2006), upon whose work this paper is heavily based, are unable to reject the null of unbiasedness in regards to the CPI core measure of inflation at the twelvemonth in-sample horizon. At the six-month in-sample forecast horizon, Johnson (1999) finds unbiasedness using the core weighted CPI but rejects the null of unbiasedness at the twelve- and eighteen-month in-sample forecast horizons due to overestimation.

In addition, Cogley (2002) finds that an exponentially smoothed measure of inflation outperforms various measures of CPI and finds unbiasedness at the eight- to ten-quarter in-sample forecast horizons. Rich and Steindel (2005) fail to reject the null of unbiasedness at the $10 \%$ significance level for the twelve-quarter in-sample forecast horizon for PCE when a longer sample period that begins in 1959 is used. They also reject the null of unbiasedness for the twelve-quarter in-sample forecast horizon when the data sample begins in 1978 for both PCE and CPI. Hence Rich and Steindel (2005) obtain contrary findings when the sample period is partitioned. The reason for rejecting the null of unbiasedness for the second sample, as stated by Rich and Steindel (2005), is due to the inflexibility of the parametric methodology, which is relaxed in this paper through the use of nonparametric methodology.

For this paper, in order to examine whether core inflation is an unbiased estimator of general inflation, the regression model of Lafléche and Armour (2006), which is based upon Cogley (2002), is used in a recursive parametric and nonparametric framework that is implemented using real-time data with the quarterly vintages of the real-time data ranging from V_1996:Q1 to V_2008:Q2.1 The regression model involves regressing the $h$-period ahead change in total inflation at time $t$ onto the difference between core inflation at time $t$ and total inflation at time $t$, which is the exclusions-from-core measure of inflation at time $t$. If core inflation is an unbiased

\footnotetext{
1 To make it easier to determine when a particular vintage of a real-time dataset as opposed to a given observation is being discussed, the notation of " $\mathrm{V}_{-}$" will appear before the vintage of the real-time dataset. For instance, V_1996:Q1 refers to the vintage of the real-time dataset
} 
predictor of inflation, then the estimated vertical intercept term should jointly be zero with the estimated slope coefficient being unity.

Along the lines of Rich and Steindel (2005) and Clark (2001), two data samples are examined for inflation persistence with the first data sample beginning from 1960:Q1 and the partitioned data sample beginning from 1984:Q1, which takes into account structural breaks. The findings of this paper are that unbiasedness is sensitive to the following: inflation measure, data sample, and vintage.

For the nonparametric estimation of the regression model, the kernelweighted least squares method (KWLS) is used, and the main reason for using nonparametric methodology is its ability to provide time-varying local regression estimators that are easy to interpret for policy matters without the need of partitioning the dataset, which is commonly done in this literature. ${ }^{2}$ Another reason for using nonparametric methodology is that the empirical distribution of inflation is typically a fat-tailed distribution, and nonparametrics is better able to capture information in the tail regions as opposed to an ordinary least squares (OLS) model (Clark 2001).

Another reason for using nonparametric methodology follows heuristically along the same line of reasoning as Cogley (2002), which presents an adaptive measure of core inflation that permits learning with the assistance of a predetermined constant gain parameter such as the one used in recursive discounted least squares, which discounts old data while assigning new data a constant weight. Nonparametrics is able to provide an adaptive framework by providing a dynamic gain parameter that is data-driven though the use of its weighing kernel, which gives more weight, i.e. higher importance to observations that are similar to the conditioning observation in terms of metric distance. For instance, a low measure of inflation is given more importance in a low inflationary period, and increasingly less weight as the similarity dissipates. Hence, new data is able to be accessed for importance, conditional on a given observation, and incorporated appropriately. For this paper, the window width, which is the smoothing parameter of the weighting kernel that facilitates this comparison, is obtained through the use of the integrated residual squares criterion (IRSC) as proposed by Fan and Gijbels (1995). ${ }^{3}$

Yet another reason for using nonparametric methodology is its potential to explain the differing results obtained by Lafléche and Armour (2006) and Johnson

released in the middle of the first quarter of 1996 with the observable data ranging from 1959:Q4 to 1995:Q4 for the first sample period.

2 For other time-varying models as it relates to monetary policy, please see Höppner, Melzer, and Neumann (2008) and Paez-Farrell (2009). 
(1999), which could be due to the larger sample size or due to the averaging method of OLS. ${ }^{4}$ The use of real time data also permits the tracing of the effects of averaging across vintages, which is one of the benefits of using real time data (Elliott 2002).

In order to statistically test whether core inflation is an unbiased measure of total inflation, the null of unbiasedness is tested through the use of the F-test for the parametric and global nonparametric models and a likelihood ratio (LR) test for the nonparametric model. ${ }^{5}$

To briefly summarize the empirical contributions of this paper, this paper finds that both the parametric and nonparametric models are in agreement that core inflation is a biased estimator of the trend of total inflation for both PCE and CPI at the one-, two-, and four-quarter in-sample forecasts for the first sample period. In regards to unbiasedness, the only strong agreement between the parametric and nonparametric models is found in the first sample period at the twelve-quarter insample forecast of CPI with the exception of two vintages in the local nonparametric model. The findings are more vintage-related in the second sample period than the first sample, which could be due to the effects of data-revision that are more readily observable in a smaller sample size, but a clear consensus cannot be firmly made at this point since new data is incorporated with the revised data. The effect of structural breaks does impact both methodologies, but much more so in the parametric case.

The structure of this paper is of the following format: Section 2 presents the parametric and nonparametric model. The empirical results are presented in Section 3 as well as a brief discussion of the univariate data. The conclusion is presented in Section 4.

\section{The Parametric and Nonparametric Models}

Without loss of generality, the discussion of the parametric and nonparametric models will be presented in reference to only one dataset, which leaves out the notion of vintages with each vintage representing a different real-time dataset that occurs with the advent of the release of new data.

In the presentation of the theoretical parametric and nonparametric models, an adaptation of the notation of Härdle and Mammen (1993) is used to present the differences between each of the methodologies. For the given pairs of observations

\footnotetext{
${ }^{3}$ In practice, the average residual squares criterion (ARSC) is used to approximate the IRSC.

${ }^{4}$ It should be noted that averaging and aggregation are not used as synonyms in this paper. For instance, the average estimators refer to the mean estimators, and aggregation refers to the use of all the local conditional nonparametric estimators.

${ }^{5}$ In much of the existing literature, such as Rich and Steindel (2005), the F-test is used.

$$
-5 \text { - }
$$
}


$\left\{\left(X_{t}, Y_{t}\right)\right\}_{t=1}^{T}$, the conditional mean of $m(\cdot)=E\left(Y_{t} \mid X_{t}=\cdot\right)$ is modelled using the following regression function with $E\left(\varepsilon_{t} \mid X_{t}\right)=0$ :

$$
Y_{t}=m\left(X_{t}\right)+\varepsilon_{t} .
$$

The Newey-West (1987) heteroskedasticity and autocorrelation consistent (HAC) covariance matrix is used in both models. For the parametric model, let $m\left(X_{t}\right)=m_{p}\left(X_{t}\right)$ with the subscript $p$ referring to the parametric regression. Specifically with $\omega_{t} \sim\left(0, \sigma_{t}^{2}\right)$, the OLS regression model is of the following forms:

$$
\begin{aligned}
& Y_{t}=m_{p}\left(X_{t}\right)+\omega_{t} \\
& Y_{t}=\alpha+\beta X_{t}+\omega_{t},
\end{aligned}
$$

which indicates that for each dataset, only one set of regression parameters is produced. Analogously for the nonparametric regression, let $m\left(X_{t}\right)=m_{n p}\left(X_{t}\right)$. The subscript $n p$ refers to the nonparametric regression. For any given $x$ and for $v_{t} \sim\left(0, \sigma^{2}(x)\right)$, the local linear least squares (LLLS) nonparametric model, which produces $T$ sets of regression parameters, is:

$$
\begin{aligned}
& Y_{t}=m_{n p}\left(X_{t}\right)+v_{t} \\
& Y_{t}=\alpha(x)+\beta(x) X_{t}+v_{t} .
\end{aligned}
$$

For both models, the possible complication of unit root(s) is avoided due to the definition of the variables used. Thus, for this paper, inflation persistence is analyzed in a stationary framework with a possible complication arising from autocorrelation, which is discussed in more detail in Sub-Sections 2.1 and 2.2.

\subsection{The Parametric Model}

In regards to studying inflation persistence, the parametric OLS model of Equation (3) is of the following form:

$$
\left(\pi_{t+h}-\pi_{t}\right)=\alpha+\beta\left(\pi_{t}^{\text {core }}-\pi_{t}\right)+\omega_{t}
$$

where $\pi_{t+h}$ is the $h$-period-ahead total inflation at time $t, \pi_{t}$ is total inflation at time $t$, $\pi_{t}^{\text {core }}$ is core inflation at time $t$ with $\omega_{t} \sim\left(o, \sigma_{t}^{2}\right)$ being the random error term with $h$ representing the in-sample forecast horizon (Clark 2001, Cogley 2002, Rich and Steindel 2005, Lafléche and Armour 2006, etc.). This makes the regressand, $Y_{t}=\left(\pi_{t+h}-\pi_{t}\right)$, the $h$-period-ahead change in total inflation at time $t$, and the 
regressor, $X_{t}=\left(\pi_{t}^{\text {core }}-\pi_{t}\right)$, is the difference between core inflation and total inflation at time $t$, which is the exclusions-from-core measure of inflation.

To statistically test for unbiasedness, in regards to core inflation being able to predict total inflation, Equation (6) is tested for the joint null hypothesis of $\alpha=0$ and $\beta=1$ using the F-test at the $5 \%$ significance level. If the null hypothesis is rejected at the $5 \%$ significance level, then this seems to indicate that there is persistence (biasedness) present in the excluded-from-core series of inflation. In order to see if and how "fast" the short-run effects of inflation dissipates, a range of $h$-period insample forecast horizons is used, which is discussed in more detail in Section 3.1.

In order to demonstrate how Equation (6) tests for unbiasedness of core inflation, suppose that $\alpha=0$ and $\beta=1$, then Equation (6) collapses to

$$
\pi_{t+h}=\pi_{t}^{\text {core }}+\omega_{t} .
$$

In interpreting the slope coefficient with $E\left(\omega_{t}\right)=0$, if $\beta=1$, this implies

$$
\begin{aligned}
& \beta_{1}=\frac{\Delta\left(\pi_{t+h}-\pi_{t}\right)}{\Delta\left(\pi_{t}^{\text {core }}-\pi_{t}\right)}=1 \\
& \Delta\left(\pi_{t+h}-\pi_{t}\right)=\Delta\left(\pi_{t}^{\text {core }}-\pi_{t}\right) \\
& \Delta \pi_{t+h}=\Delta \pi_{t}^{\text {core }} .
\end{aligned}
$$

Thus, Equation (9) states that the change in current core inflation at time $t$ is able to capture the change in the $h$-period ahead in-sample forecast of total inflation.

Furthermore, suppose $\alpha=0$ and $\beta<1$, then the following is inferred:

$$
\Delta \pi_{t+h}<\Delta \pi_{t}^{\text {core }} .
$$

Equation (10) implies that the exclusions-from-core series of total inflation are overstated with the implication being that the change in the $h$-period ahead in-sample forecast of total inflation is below the change in trend inflation (Johnson 1999, Lafléche and Armour 2006).

Alternatively, suppose $\alpha=0$ and $\beta>1$, then

$$
\Delta \pi_{t+h}>\Delta \pi_{t}^{\text {core }} .
$$

Equation (11) infers that the change in the excluded-from-core series of inflation is less than the change of future inflation. The transitory movements from the exclusions-from-core series are then said to be understated (Johnson 1999, Lafléche and Armour 2006). Analogously, the change in the $h$-period ahead in-sample forecast of total inflation is above the change of trend inflation. 
Analogous to Cogley (2002) and Rich and Steindel (2005), the Newey-West (1987) HAC covariance matrix is used to form the standard errors and the t-statistics for Equation (6) with the lags of the Bartlett kernel reflecting the length of the $h$-period in-sample forecasts. ${ }^{6}$ Due to the construction of the variables used in the regression model, which includes the $h$-period in-sample forecast horizons, the Newey-West (1987) HAC is used to account for autocorrelations caused by the overlapping time period of variables and any potential conditional heteroskedasticity (Rich and Steindel 2005). ${ }^{7}$

In regards to the hypothesis testing of the parametric model, the F-test is used. For the critical values the standard F-statistic critical values are used as opposed to the Dickey-Fuller F-statistic critical values since all the variables in the model are stationary as is further discussed in Section 3.1.

\subsection{The Nonparametric Model}

The discussion and analysis of the exclusions-from-core measures of inflation in the nonparametric model are analogous to that of the parametric model, but the implementation is very different due to its flexibility. The flexibility as well as the minimax properties of the LLLS nonparametric regression model as given by Equation (5) permits a more thorough analysis of inflation persistence by providing $T$ sets of regression parameters for a dataset with $T$ number of observations (Wand and Jones 1995, Atkeson, Moore, and Schaal 1999, and Fan and Gijbels 1996).

LLLS is a KWLS form of nonparametric methodology, which amounts to fitting a line within the window width that is conditional on a given observation, $x$. The KWLS form of local polynomial fitting is able to provide both local nonparametric regression parameters conditional on any given $x$, such as $\alpha_{t}(x)$ and $\beta_{t}(x)$ with the subscript $t$ referring to the $t^{\text {th }}$ local nonparametric regression, which are analogous to the parameters of Equation (5). The set of global nonparametric regression parameters are formed by taking the average of all the local conditional nonparametric regression parameters of Equation (5), which are:

$$
(1 / T) \sum_{t=1}^{T} \alpha_{t}(x) \text { and }(1 / T) \sum_{t=1}^{T} \beta_{t}(x) .
$$

For this paper, the degree of the local polynomial is one since it is able to reduce the bias in the boundary regions without increasing the variance by much

\footnotetext{
${ }^{6}$ Regarding the estimation of the Newey-West HAC variance-covariance matrix, the procedure written by Mika Vaihekoski $(1998,2004)$ is used and is able to be obtained from the following web address: http://www2.lut.fi/ vaihekos/mv_econ.html\#e3.

7 In estimation, as the in-sample forecast horizon increases, the level of autocorrelation in the residuals also increases, which further necessitates the need for the Newey-West (1987) HAC. 
(Ruppert and Wand 1994, Pagan and Ullah 1999). For any given $x$, the univariate Gaussian kernel is used as the smoothing function, which is of the form:

$$
K=\sum_{t=1}^{T} K(\psi)
$$

where $K(\psi)=\frac{1}{(2 \pi)^{\frac{l}{2}}} \exp \left(-\frac{1}{2}\left(\frac{x_{t}-x}{d_{T}}\right)^{2}\right)$ with $\psi=\left(\frac{x_{t}-x}{d_{T}}\right)$ and $d_{T}$ referring to the window width, which is the smoothing parameter of the model. The window width, $d_{T}$, is used in the kernel to help determine the "nearness" or "farness" based on the conditioning observation, $x$ (Atkeson, Moore, and Schaal 1997).

The flexibility provided by nonparametrics is due to its window width since it is able to provide local regression parameters conditional on any given observation, $x .^{8}$ This advantageous feature of nonparametrics is also the Achilles' heel since the choice of window width can severely affect the estimation of the local conditional regression parameters. ${ }^{9}$ For this paper, the IRSC method, which is a pre-asymptotic data-driven residual-based window width approach of Fan and Gijbels (1995) that minimizes the normalized weighted residual sum of squares, is used to obtain a constant window width for each dataset. ${ }^{10}$ Concerning the window width, by choosing a constant window width that minimizes the ARSC, the mean squared errors is minimized thereby minimizing the squared bias and the variance of the regression parameter (Fan and Gijbels 1995, Marron 1988, Härdle and Tsybakov 1997).

An additional benefit of using nonparametric methodology is that it takes into account heteroskedasticity since $E\left(v^{2} \mid X=x\right)=\sigma^{2}(x)$, but when it comes to hypothesis testing, autocorrelation is not addressed (Robinson 1998). The presence of autocorrelation does not affect the parameters, but it does affect the hypothesis tests by producing standard errors that could be underestimated, which would then overestimate the test statistic.

In regards to dealing with autocorrelation, Cai, Kuan, and Sun (2008) propose a nonparametric GMM methodology that combines orthogonality conditions and LLLS as a method of dealing with autocorrelation as does Creel (2008) except Creel's (2008) work mainly concerns general dynamic latent variable models. Creel (2008) discusses

\footnotetext{
8 The leave-one-out form of least squares cross-validation is not used for this paper due to periods of instability when estimated (Marron 1988, Härdle 1994, Wand and Jones 1995, Fan and Yao 1998, Cai, Fan, and Yao 2000, Fujiwara and Koga 2004).

${ }^{9}$ Another potential weakness in nonparametric methodology is the Curse of Dimensionality, which is not an issue for this paper since this is a univariate model (Cleveland and Devlin 1988, Härdle and Linton 1994).
} 
combining kernel smoothing techniques to obtain conditional moments and the Newey-West (1987) HAC, which itself involves a nonparametric kernel function, i.e. the Bartlett kernel, as is done in this paper in order to remove autocorrelation from the local conditional standard errors, which are needed for hypothesis testing. ${ }^{11}$ Robinson (1998) method of dealing with autocorrelation is more aptly suited for the nearest-neighbour nonparametric approach.

A more generalized method for dealing with autocorrelation is presented in this paper, which to the author's best knowledge has not been previously presented. Since the nonparametric error terms are obtained by minimizing the residual sum of squares from Equation (5), these error terms are used to form the T-test for statistical significance of the parameters which utilizes the Newey-West (1987) HAC covariance matrix (Wasserman 2006).12

Regarding the joint hypothesis test of unbiasedness of the exclusions-fromcore measures of inflation of the nonparametric regression of Equation (5), the null hypothesis of the following form:

$$
\mathrm{H}_{0}: \alpha(x)=0 \text { and } \beta(x)=1
$$

for each and every $x$, with the alternate hypothesis being, $\mathrm{H}_{1}$ : Not $\mathrm{H}_{0}$. This translates into testing $T$-number of regression parameters for unbiasedness since there are $T$ number of observations in a given dataset.

Concerning the overall goodness of fit for all the local nonparametric regression estimates, Fan, Zhang, and Zhang's (2001) generalized nonparametric LRtest in a varying-coefficients model is used since the error terms are stationary and since this test takes into account heteroskedasticity. Specifically, the generalized nonparametric LR-test is a hypothesis test that uses the weighted residual sum of squares with the same weighting matrix being used for both the null and alternate hypotheses in order to keep the comparison as similar as possible, which is important since the weighting is based on metric distance. The benefit of using the aforementioned LR-test, which assumes $E(v \mid X=x)=0$ and $E\left(v^{2} \mid X=x\right)=\sigma^{2}(x)$, is that the $\chi^{2}$ critical values may be used. The LR-statistic of $\lambda_{T}$ looks at the aggregated nonparametric regression model and is of the form:

10 For other papers that use the residual-based window, please see Cai and Chen (2005), Cai (2007), Fan and Yao (1998), Chauvet and Tierney (2008), etc.

11 Creel (2008) does not use the Newey-West (1987) HAC variance-covariance matrix due to unreliability in the general dynamic latent variable model.

12 Sometimes in nonparametric estimation, the average nonparametric regression parameters are used in an OLS framework to obtain the error terms, but this is not advisable since these 


$$
\lambda_{T}=\left[\operatorname{Ln}\left(H_{1}\right)-\operatorname{Ln}\left(H_{0}\right)\right]=\left(\frac{T}{2}\right) \log \left(\frac{R S S_{0}}{R S S_{1}}\right)
$$

where $R S S_{0}$ is the residual sum of squares under the null (the restricted model) and $R S S_{1}$ is the residual sum of squares of the alternate (the unrestricted model). Hence, a generalized nonparametric LR test produces only one test statistic for each dataset.

\subsection{Model Evaluation}

In keeping within the framework of the literature in this area such as Cogley (2002), Johnson (1999), Lafléche and Armour (2006), and Rich and Steindel (2005), etc., the adjusted R-squared, $\bar{R}^{2}$, is used as a method for model comparison, which demonstrates how well the variation of the dependent variable is explained by the model (Hayfield and Racine 2008).

Given the two different ways to model inflation persistence, the metric distance between $m_{n p}\left(X_{t}\right)$ from Equation (4) and $m_{p}\left(X_{t}\right)$ from Equation (2) is tested for statistical significance using Härdle and Mammen's (1993) wild bootstrap test. As stated in Li and Racine (2007) under the null hypothesis, the population mean is replaced with the sample mean in forming the estimated test statistic, $\hat{N}_{H M}$ where

$$
\hat{N}_{H M}=\left(\frac{1}{T}\right) \sum_{t=1}^{T}\left[\hat{m}_{n p}\left(X_{t}\right)-\hat{m}_{p}\left(X_{t}\right)\right]^{2}
$$

with the alternate hypothesis being $\hat{N}_{H M}>0$.

\section{Empirical Results}

Since the empirical portion involves five in-sample forecasts for two measures of inflation PCE and CPI, which means that two regression models are estimated and discussed for three different methodologies, which are the parametric, global nonparametric, and local nonparametric methodologies as well as five in-sample forecast horizons, Legend 1 to Legend 4 are provided in order to help with the interpretation of the tables.

Concerning the real-time data set, even though the results for V_1999:Q4 and V_2000:Q1 are presented for the regressions involving the PCE measure of inflation, the results are unreliable due to issues that stem from the PCE. V_1999:Q4 is problematic because much of the dataset had to be interpolated since the real-time data of V_1999:Q4 actually begins with 
observation 1994:Q1. The data in V_2000:Q1 is problematic due to inconsistencies in the data collection methodology. ${ }^{13}$ In comparing V_2000:Q1 to other vintages, the change in data of V_2000:Q1 is picked up by the nonparametric methodology as evidenced by the smaller window width as is shown in Tables 6 and 7.

\subsection{Data and Univariate Analysis}

The measures of core PCE, PCE, and CPI are obtained in real-time and are available from the Philadelphia Fed. The seasonally-adjusted core CPI is obtained from the St. Louis Federal Reserve Economic Data (F.R.E.D) since it is not provided in real-time. ${ }^{14}$ The real-time dataset begins with first vintage being V_1996:Q1 and the last vintage being V_2008:Q2. Only 50 vintages are examined since these are the only available vintages of core PCE and PCE. Vintages of CPI go farther back, but in order to keep the real-time data analysis as symmetric as possible especially since one of the purposes of this paper is to examine whether PCE or CPI is better able to model inflation persistence. For the first sample period, each of the 50 vintages begins with 1959:Q4 before the calculation of inflation.

Regarding the first sample period, the calculation of inflation begins with 1960:Q1 to 2008:Q1 for the very last vintage used in this paper, which is V_2008:Q2. This long range of data is deliberately used in order to capture the long run trend in the core and total measures of inflation (Rapach 2003, Gagnon 2008). ${ }^{15}$ Since some observations are lost in forming the leading variables, the number of observations in each of the regressions varies according to the in-sample forecast horizons of $h$ with $h$ being defined as follows: $h=\left\{h_{1}, h_{2}, h_{3}, h_{4}, h_{5}\right\}=\{1,2,4,8,12\}$. The number of observations for each regression is presented in Legend 4.

For this paper, annualized quarterly measures of inflation are used. Quarterly PCE and quarterly core PCE data are available but only monthly seasonally-adjusted real-time data of CPI is available from the Federal Reserve Bank of Philadelphia, which is adjusted accordingly to produce annualized quarterly data. ${ }^{16}$

useful for hypothesis testing purposes.

13 The interpolation method for V_1999:Q4 was kindly provided by Dean Croushore as was the information regarding V_2000:Q1.

${ }^{14}$ For a more complete description of real-time data, please see Croushore and Stark (2001), Croushore (2007), and the Federal Reserve Bank of Philadelphia.

${ }^{15}$ As is later shown in Sections 3.2 and 3.3, the inclusion of a long period of time with potential structural breaks dampens the effectiveness of the regression model for both the parametric and nonparametric models.

${ }^{16}$ For more information regarding the collection of real-time CPI, please visit the Federal Reserve Bank of Philadelphia website of:

http://www.philadelphiafed.org/econ/forecast/real-time-data/data-files/CPI/. 
Graphs 1A and 1B respectively depict PCE and Core PCE and CPI and Core CPI for the last vintage of V_2008:Q1. To describe generally and briefly the relationship between total inflation and core inflation using both PCE and CPI, the relationship appears to be as follows:

(i.) Pre-1982: Total inflation and core inflation appear to share a similar comovement,

(ii.) Post-1982 to 1999: Core inflation appears to either over- or under-estimate total inflation, which shows a great deal of unique local behaviour, and

(iii.) Post-1999: The difference between total and core inflation becomes even more pronounce and displays some local divergence.

This seems to indicate the possible presence of a structural break especially around 1982. Based upon the findings of the Bai-Quant Test for Structural Change (1997), a structural break for core PCE, PCE, core CPI, and CPI are found respectively at the following dates: 1983:Q2, 1981:Q2, 1980:Q3, and 1981:Q4.17 For the purposes of keeping the analysis as similar as possible, the second sample period for each vintage begins in 1983:Q4 before the calculation of inflation with the vintages examined in this paper being analogous to the first sample period.

By the construction of the regressand and the regressor, the regression models of Equations (3) and (5) are stationary. Furthermore, the regressand, regressor, and residuals of the regression model are individually tested for stationarity and are found to be $\mathrm{I}(0)$ by both the Augmented Dickey-Fuller Test and the Phillips-Perron Test. These findings are also confirmed by Clark (2001) and Rich and Steindel (2005).

\subsection{Parametric and Global Nonparametric Empirical Results}

As a method of organizing the estimation results for discussion, " $\mathrm{A}$ " denotes the information regarding the regression involving the PCE measure of inflation, and "B" denotes the information regarding the regression involving the CPI.

\subsubsection{First Sample Period: Beginning from 1960:Q1}

As a means to compare central tendency for all fifty vintages of real-time data from V_1996:Q1 to V_2008:Q2, the parametric OLS and the global nonparametric, i.e. the average of the local nonparametric estimated regression coefficients are obtained respectively from Equations (6) and (12), and are found to produce vastly different results. As Table $1 \mathrm{~A}$ shows, the estimated slope coefficients of the parametric case is

\footnotetext{
17 Bruce Hansen's (2001) program for testing for structural changes is used and is able to be obtained from the following web address:

http://www.ssc.wisc.edu/ bhansen/progs/jep_01.html .
} 
smaller than its global nonparametric counterpart for the first three in-sample forecast horizons of one, two, and four quarters. ${ }^{18}$ The estimated parametric slopes involving the in-sample forecast horizons of eight- and twelve- quarters is closer to unity and larger on average when compared to its global nonparametric counterpart, which is shown in Table $1 \mathrm{~A}$.

The global nonparametric vertical intercepts tend to be negative and larger in absolute value terms than its parametric counterpart with each increasing in magnitude as the in-sample forecast horizon increases. The differences in the vertical intercept are important to point out because as mentioned by Rich and Steindel (2005), the inflexibility of the vertical intercept is one of the problems of the parametric model, especially when parameter instability is suspected. The regression estimates for Regression B, which involves the CPI measure of inflation, are similar to the results of Regression A. A summary of the average behaviour of the estimated regressions coefficients for both the parametric and global nonparametric cases for all in-sample forecast horizons for Regression B are presented in Table 1B.

The standard deviations, t-statistics, and related p-values for both the parametric and global nonparametric case are computed using the Newey-West HAC variance-covariance (1987) in order to take into account autocorrelation, which increases as the in-sample forecast horizon increases. In Tables $1 \mathrm{~A}$ and $1 \mathrm{~B}$, the standard deviations, t-statistics, and related p-values are provided for the estimated global nonparametric coefficients as a means of comparing central tendency against the parametric model but are not an exact analogous comparison of methodologies due to the formation of the residuals.

In comparing the $\bar{R}^{2}$, a summary of the averages of the $\bar{R}^{2}$ across vintages and for all five in-sample forecast horizons is provided in Table 3 for Regressions A and B. For all methodologies, the latter vintages combined with higher in-sample forecast horizons produce an overall higher $\bar{R}^{2}$, which could possibly be partly due to data revision or the increase in sample size. Rich and Steindel (2005) also find that the $\bar{R}^{2}$ increases as the in-sample forecast horizons increase.

For the parametric Regression A, the lowest $\bar{R}^{2}$ of 0.017 is for the regression involving the four-quarter in-sample forecast horizon with the highest $\bar{R}^{2}$ of 0.165 involving the regression for the twelve-quarter in-sample forecast horizon. In the first sample period, when the structural break is not taken into account, the explanatory power of the variability of the dependent variable increases by $61 \%$ at the minimum

\footnotetext{
18 Due to an attempt at limiting space, all the results are not provided in this paper but are available upon request.
} 
for Regression A and 86\% for Regression B, which occurs in the twelve-quarter insample forecast horizon, and by 1,329\% at the maximum for PCE and 1,214\% for CPI, which occurs in the four-quarter in-sample forecast horizon.

In regards to the joint hypothesis test for unbiasedness of Equation (6), it is determined that unbiasedness occurs when the null hypothesis of $\alpha=0$ and $\beta=1$ fails to be rejected at the $5 \%$ significance level through the use of the F-test. So, the farther away the p-value gets from 0.05 , the more strongly the null is failed to be rejected. For this paper, unbiasedness refer to the exclusions-from-core measures of inflation not having an impact on the $h$-period ahead forecast of inflation, which implies that core inflation is able to be capture the overall trend of inflation. For the first three in-sample forecasts of one-, two-, and four- quarters, the null of unbiasedness is strongly rejected with a p-value of 0.00 for both the parametric and global nonparametric cases for Regressions $A$ and $B$ as is summarized in Tables $5 \mathrm{~A}$ and 5B. The estimated slope coefficients for Regressions A and B, which are less than unity, imply that a scenario as described by Equation (10) has occurred meaning that the changes in the $h$-period in-sample forecast of total inflation are below the changes in trend inflation.

For the parametric case, unbiasedness is found in the eight- and twelvequarter in-sample forecasts of PCE and CPI, but it should be noted that the average $\bar{R}^{2}$ for Regression A is $11 \%$ and $16.5 \%$ and for Regression B, is $5.4 \%$ and $8.6 \%$ for the eight- and twelve-quarter in-sample forecast horizons. Unbiasedness is not found in any of the global nonparametric regressions despite them being able to explain more of the variation in the regressand for all regressions involving PCE and CPI.

\subsubsection{Second Sample Period: Beginning from 1984:Q1}

In taking into account a structural break, the parametric and global nonparametric models produce different results than that of the first sample period. Table 2A presents the average estimated coefficients for the regressions involving PCE for all fifty vintages. Except for the regression involving the first in-sample forecast horizon, the estimated slope coefficients are closer to unity that the global nonparametric slope coefficients.

Regarding Regression B, which concerns the CPI, all the estimated vertical intercepts for the parametric and global nonparametric models are negative except for the global nonparametric regressions involving the two-quarter in-sample forecast horizon, which is essentially zero. As with Regression A, the average estimated slope coefficients are closer to unity especially for the latter three in-sample forecast horizon. The twelve-quarter in-sample forecast horizon for both the parametric and 
global nonparametric regressions are extremely close in magnitude. In the two methodologies, all the estimated slope coefficients are statistically significant as is shown in Table 2B.

Once the structural break is taken into account, the $\bar{R}^{2}$ of the parametric model improves dramatically when compared to the first sample period as is demonstrated in Tables 3 and 4. Despite this, when compared to the parametric model, the global nonparametric model is still able to explain at a minimum $41 \%$ more of the variation in the $h$-quarter change in PCE and $26 \%$ of the variation in the $h$-quarter change in CPI in the four-quarter in-sample forecast horizon. The most dramatic increase involves the one-quarter in-sample forecast horizon with the global nonparametric model being able to explain 95\% more of the variation in the regressand for Regression $\mathrm{A}$ and $125 \%$ more of the variation in the regressand for Regression B than the parametric model.

Concerning the joint hypothesis test with a null of unbiasedness, the results of the F-test in the parametric model are vintage-related as demonstrated by Tables $5 \mathrm{~A}$ and 5B.19 For both Regressions A and B, the null of unbiasedness is rejected for the global nonparametric model at the 5\% significance level for all in-sample forecast horizons. Contrary to the first sample period, the parametric model, at least for the latter vintages, the null of unbiasedness fails to be rejected at the $5 \%$ significance level for all in-sample forecast horizons except for the one-quarter in-sample forecast horizon involving CPI. Thus, regarding unbiasedness, the parametric model and the global nonparametric model do not concur on unbiasedness for any of the in-sample forecast horizons in the second sample period.

\subsection{Local Nonparametric Empirical Results}

The window widths for each vintage and for each sample period are calculated using Fan and Gijbels' (1995) IRSC method as described in Sub-Section 2.2 and is available upon request. The range of the window width for the regressions involving PCE is from 0.27 to 0.20 for the first sample period and from 0.22 to 0.05 for the second sample period. For the regressions involving the CPI, the window widths for the first sample period range from 0.29 to 0.18 and from 0.46 to 0.19 for the second sample period.

\footnotetext{
${ }^{19}$ Regarding the parametric model for the second sample period, the null of unbiasedness also fails to be rejected at the $5 \%$ significance level for the following sporadic vintages not specifically mentioned in Table 5A: $h_{1}: V_{-} 1999: Q 4$ to V_2000:Q1 and V_2001:Q4 to V_2002:Q1, $\mathrm{h}_{4}$ : V_1999:Q4, V_2001:Q3 toV_2001:Q4, and V_2002:Q4 to V_2003:Q2, h5: V_1996:Q1, V_1997:Q3, V_1999:Q4, V_2003:Q3. 
For both sample periods, the Härdle and Mammen (1993) wild bootstrap test as depicted in Equation (16) produces p-values that are less than 0.05 for all fifty vintages in both sample periods. This means that the parametric and nonparametric models are statistically different. Based on the fact that the local nonparametric model produces higher $\bar{R}^{2}$, which are presented in Tables 3 and 4, and the results of the Härdle and Mammen (1993) wild bootstrap test, the local nonparametric model is better able to model inflation persistence than the parametric model.

\subsubsection{First Sample Period: Beginning from 1960:Q1}

For Regression A for V_2008:Q2, it might seem to be a mistake that conditional on 2006:Q4, the estimated vertical intercept for the two-quarter in-sample horizon is 20.75 , and the estimated slope is -5.62 , but when examining the fitted values, the local nonparametric fitted value is 5.027 and the parametric fitted value is 1.14 with the actual value of the two-quarter ahead in-sample forecast of inflation being 5.07. This is just one of many instances where nonparametrics is able to pick up the curvature of the data better than the parametric version, which helps to explain why the nonparametric model has smaller residuals. Hence, regarding the interpretation of nonparametric models, it is important to not only look at the estimated coefficients but more importantly at the fitted values in order to determine if the local nonparametric estimates "make sense" and are not an anomaly in the sense of being window width driven (Härdle 1994, Wand and Jones 1995).

Graphs 2A and 2B and Graphs 3A and 3B illustrate the estimated fitted values of the parametric and local nonparametric values along with the actual values of the four-quarter change and the twelve-quarter change in total PCE and total CPI, respectively. With the inclusion of the structural break, the local nonparametric model is better able to capture the actual in-sample forecasts of total inflation despite there being a great deal of local curvature with the exception of the oils shock of the mid 1970 's and the turmoil of the early 1980's, thus explaining the much higher $\bar{R}^{2}$ for both Regressions A and B.

Table 6A displays the results of the Fan, Zhang, and Zhang's (2001) generalized nonparametric LR-test for Regression A, with the null of conditional unbiasedness being rejected for the regressions involving all in-sample forecast horizons except for V_1999:Q4, which is problematic since much of the dataset needed to be interpolated. A summary of the joint hypothesis tests of the aggregated local nonparametric estimates for both Regressions A and B can be found in Tables 5A and 5B. Regarding Regression B, as shown in Table 6B; Fan, Zhang, and Zhang's (2001) generalized nonparametric LR-test also rejects the null of unbiasedness for all in-sample forecast horizons except for the twelve-quarter in-sample forecast horizon with the exceptions 
of vintages, V_2005:Q1 to V_2006:Q1. Hence, according to Fan, Zhang, and Zhang's (2001) generalized nonparametric LR-test, only for CPI and only at the twelve-quarter mark does core CPI capture the general trend of total CPI in the first sample period.

Hence, in regards to the empirical estimation of Regressions A and B, this paper finds that both the parametric and nonparametric models agree upon unbiasedness in regards to the twelve-quarter in-sample forecast of CPI only. Although nonparametrics is able to provided conditional local estimates, the effects of data revision are much more difficult to pinpoint with any degree of certainty because of the continual updating of the real-time dataset with new information. In order to isolate the effect of data revisions, one must keep the number of observations the same while varying only the vintages; this is left for future research.

\subsubsection{Second Sample Period: Beginning from 1984:Q1}

Graphs $4 \mathrm{~A}$ and $4 \mathrm{~B}$ and Graphs $5 \mathrm{~A}$ and $5 \mathrm{~B}$ demonstrates the estimated fitted values of both the parametric and local nonparametric values along with the actual values of the one-quarter change and the four-quarter change in total PCE and total CPI, respectively. With the removal of the structural break, the parametric model performs better, but the nonparametric model still out performs the parametric model. The regressions involving the one-quarter in-sample forecast horizon, as is found in Graphs 4A and 4B, are illustrated since the difference in terms of explanatory power between the parametric and nonparametric models, as described by the $\bar{R}^{2}$ is the highest. Similarly, the regressions involving the four-quarter in-sample forecast horizon are depicted since they involve the lowest in terms of the difference of the $\bar{R}^{2}$ between the parametric and local nonparametric models.

In regards to Fan, Zhang, and Zhang's (2001) generalized nonparametric LRtest for the aggregate nonparametric model, for Regression B, which involves CPI, for the same in-sample forecast horizon such as the eight-quarter in-sample forecast horizon, the results of the joint hypothesis test for unbiasedness are mixed, which is analogous to the finding of the parametric model with a summary of the results being provided in Tables 7A and 7B. Concerning Regression A, the earlier vintages of the four-quarter in-sample forecast horizon find unbiasedness while the vintages after and not including V_2002:Q4 find that the aggregated nonparametric model to be biased.

\section{Conclusion}

The contributions of this paper are the strongest on the two main fronts of methodology and empirical results and the third front of real-time data analysis being inconclusive. Concerning the methodology, the innovation of a nonparametric GMM 
method is used to account for autocorrelation at the local nonparametric level through the use of the Newey-West HAC estimator, which to the author's best knowledge has not been previously presented. In addition, as it pertains to the nonparametric methodology, this paper proposes comparing the parametric benchmark with the aggregate local nonparametric model instead of just using the global nonparametric estimators, which are the average of the local nonparametric estimates as is typically done in the nonparametric literature. It should be noted that the global nonparametric estimators are presented as a measure of central tendency but hypothesis tests based on using these measures are inadequate since the residuals that are not formed by minimizing the residual sum of squares.

Regarding the empirical results of capturing inflation persistence, this paper finds that core inflation, which is total inflation minus the volatile components of food and energy, does not appear to consistently capture the overall trend of total inflation regardless of whether PCE or CPI is used. Of the two measures, CPI performs better than PCE in regards to modelling inflation persistence. The findings of unbiasedness especially in the second sample period can possibly be vintage-related, which could be due to the incorporation of new data or data-revisions. This is an argument in favour of using real-time data, but this warrants further investigation. The parametric model is more likely to be unbiased meaning that core inflation is able to predict the $h$-period ahead changes in total inflation for both PCE and CPI but is also vintage-related and sample-related in spite of being able to explain less of the variation in the regressand which makes one question the findings of unbiasedness in the parametric model.

This paper also finds that the presence of a structural break affects the empirical findings. In the presence of a large structural break such as the one that occurs in the early 1980's for PCE, core PCE, CPI, and core CPI, the ability of the parametric model to explain the variability of the $h$-period ahead change in total inflation is dramatically decreased when compared to the sub-sample period with the removal of the structural break. The local nonparametric model fares better in the presence of a large structural break, but still, once the structural break is taken into account, the explanatory power of the local nonparametric model as captured by the $\bar{R}^{2}$ also increases drastically, but not as drastically as the parametric model.

The contribution of this paper is regards to the exact effect of data-revision on measuring the persistence of inflation is uncertain. The use of a recursive methodology in a parametric and non-parametric framework is not enough to isolate the effects of data-revision. In the presence of data revision, even when new data is incorporated by using a dynamic gain parameter, it is not clear whether the change 
produced in the local conditional regression is from the incorporation of new data or due to data revision. Hence, this paper finds that it is important to isolate the effect of data revisions by keeping the dataset constant and varying only the vintages, which is left for future research.

\section{References}

Atkeson, C.G., Moore, A.W., and Schaal, S. (1997), "Locally Weighted Learning," Artificial Intelligence Review, 11, 11-73.

Bai, J. (1997), "Estimating Multiple Breaks One at a Time," Economic Theory, 13:3, 315352.

Cai, Z. (2007), "Trending Time-Varying Coefficient Time Series Models with Serially Correlated Errors," Journal of Econometrics, 136, 163-188.

Cai, Z. and Chen, R. (2005), "Flexible seasonal time series models," Advances in Econometrics Volume Honoring Engle and Granger, B. T. Fomby and D. Terrell, eds., Orlando: Elsevier.

Cai, Z., Fan, J., and Yao, Q. (2000), "Functional-Coefficient Regression Models for Nonlinear Time Series," Journal of the American Statistical Association, 95:451, 941956.

Cai, Z., Kuan, C., and Sun, L. (2008), "Nonparametric Pricing Kernel: Estimation and Test," Working Paper.

Chauvet, M. and Tierney, H.L.R. (2008), "Real-Time Changes in Monetary Transmission -A Nonparametric VAR Approach," Working Paper.

Clark, T.E. (2001), “Comparing Measures of Core Inflation," Federal Reserve Bank of Kansas City Economic Review, 86:2 (Second Quarter), 5-31.

Cleveland, W.S. and Devlin, S.J. (1988), "Locally Weighted Regression: An Approach to Regression Analysis by Local Fitting," Journal of the American Statistical Association, 83:403, 596-610.

Cogley, T. (2002), "A Simple Adaptive Measure of Core Inflation," Journal of Money, Credit, and Banking, 43:1, 94-113.

Creel, M. (2008), "Estimation of Dynamic Latent Variable Models Using Simulated Nonparametric Moments," Unitat de Fonaments de l'Anàlisi Econòmica (UAB) and Institut d'Anàlisi Econòmica (CSIC), UFAE and IAE Working Papers 725.08, revised June.

Croushore, D. (2007), "Revisions to PCE Inflation Measures: Implications for Monetary Policy," Federal Reserve Bank of Philadelphia, Working Paper.

Croushore, D., and Stark, T. (2001), "A Real-Time Data Set for Macroeconomists," Journal of Econometrics 105, 111-130. 
Elliott, G. (2002), "Comments on 'Forecasting with a Real-Time Data Set for Macroeconomists'," Journal of Macroeconomics, 24:4, 533-539.

Fan, J. and Gijbels, I. (1995), "Data-Driven Selection in Polynomial Fitting: Variable Bandwidth and Spatial Adaptation," Journal of the Royal Statistical Society: Series B 57, 371-394.

Fan, J. and Gijbels, I. (1996), Monographs on Statistics and Applied Probability 66, Local Polynomial Modeling and Its Applications. London: Chapman and Hall.

Fan, J. and Yao, Q. (1998), "Efficient Estimation of Conditional Variance Functions in Stochastic Regressions," Biometrika, 85:3, 645-660.

Fan, J., Zhang, C., and Zhang, J. (2001), "Generalized Likelihood Ratio Statistics and Wilks Phenomenon" The Annals of Statistics, 29, 153-193.

Fujiwara, I. and Koga, M. (2004), "A Statistical Forecasting Method for Inflation Forecasting: Hitting Every Vector Autoregression and Forecasting under Model Uncertainty," Monetary and Economic Studies, Institute for Monetary and Economic Studies, Bank of Japan, 22:1, 123-142, March.

Gagnon, J.E. (2008), "Inflation Regimes and Inflation Expectations," Federal Reserve Bank of St. Louis Review, 90:3-Part 2.

Hansen, B.E. (2001), GAUSS Program for Testing for Structural Change, http://www.ssc.wisc.edu/ bhansen/progs/jep_01.htm. Accessed 5 Dec 2008.

Härdle, W. (1994), Applied Nonparametric Regression, Cambridge: Cambridge University Press.

Härdle, W. and Linton, O. (1994), "Applied Nonparametric Methods," Handbook of Econometrics, IV, R.F. Engle and D.L. Mc Fadden, eds., Amsterdam: North-Holland.

Härdle, W. and Mammen, E. (1993), "Comparing Nonparametric versus Parametric Regression Fits," The Annals of Statistics, 21:4, 1926-1947.

Härdle, W. and Tsybakov, A. (1997), "Local Polynomial Estimator of the Volatility Function in Nonparametric Autoregression," Journal of Econometrics, 81, 223-242.

Hayfield, T. and Racine, J. (2008), "Nonparametric Econometrics: The NP Package," Journal of Statistical Software, 27:5, 1-32.

Höppner, F., Melzer, C., and Neumann, T. (2008), “Changing Effects of Monetary Policy in the US-evidence from a Time-varying Coefficient VAR," Applied Economics, 40:18, 2353-2360.

Johnson, Marianne (1999), "Core Inflation: A Measure of Inflation for Policy Purposes," Proceedings from Measures of Underlying Inflation and their Role in Conduct of Monetary Policy-Workshop of Central Model Builders at Bank for International Settlements, February.

Lafléche, T. and Armour, J. (2006), "Evaluating Measures of Core Inflation," Bank of Canada Review, Summer.

Li, Q. and Racine, J. (2007), Nonparametrics Econometrics: Theory and Practice, Princeton University Press, Princeton. 
Marron, J.S. (1988), "Automatic Smoothing Parameter Selection: A Survey," Empirical Economics, 13, 187-208.

Newey, W.K., and West, K.D. (1987), “A Simple, Positive, Definite, Heteroskedasticity and Autocorrelation Consistent Covariance Matrix," Econometrica, 55:3, 765-775.

Paez-Farrell, J. (2009), "Monetary policy rules in theory and in practice: evidence from the UK and the US," Applied Economics, 41:16, 2037-2046.

Pagan, A and Ullah, A. (1999), Nonparametric Econometrics, Cambridge: Cambridge University Press.

Rapach, D. (2003), "International Evidence on the Long-Run Impact of Inflation," Journal of Money Credit and Banking, 35:1, 23-45.

Rich, R. and Steindel, C. (2005), "A Review of Core Inflation and an Evaluation of Its Measures," Federal Reserve Bank of New York Staff Report No. 236, December.

Robinson, P.M. (1998), "Inference Without-Smoothing in the Presence of Autocorrelation," Econometrica, 66:5, 1163-1182.

Ruppert, D. and Wand, M. P. (1994), "Multivariate Locally Weighted Least Squares Regression," The Annals of Statistics, 22, 1346-1370.

Silver, M. (1997), "Core Inflation Measure and Statistical Issues in Choosing among Them," International Monetary Fund Working Paper, WP/06/97.

Vaihekoski, M. (2004), "nwest", GAUSS Procedure for the Newey-West heteroskedasticity and autocorrelation consistent (HAC) covariance matrix, http://www2.lut.fi/ vaihekos/mv_econ.html\#e3. Accessed 8 July 2008.

Wand, M. P. and Jones, M.C. (1995), Kernel Smoothing, Chapman \& Hall, London.

Wasserman, L. (2006), All of Nonparametric Statistics, Springer, New York. 

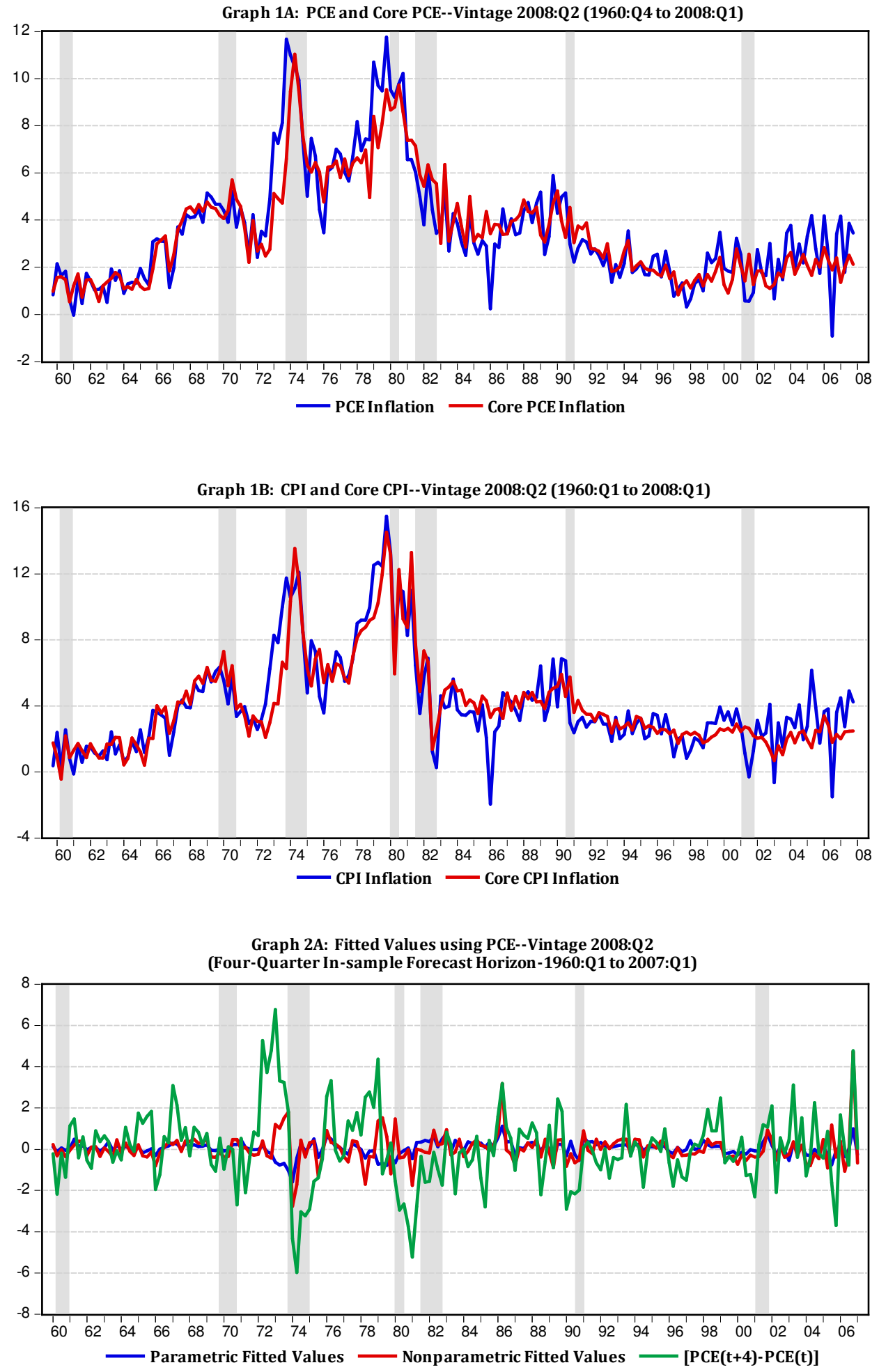
Graph 2B: Fitted Values using CPI--Vintage 2008:02

(Four-Quarter In-sample Forecast Horizon-1960:Q1 to 2007:Q1)

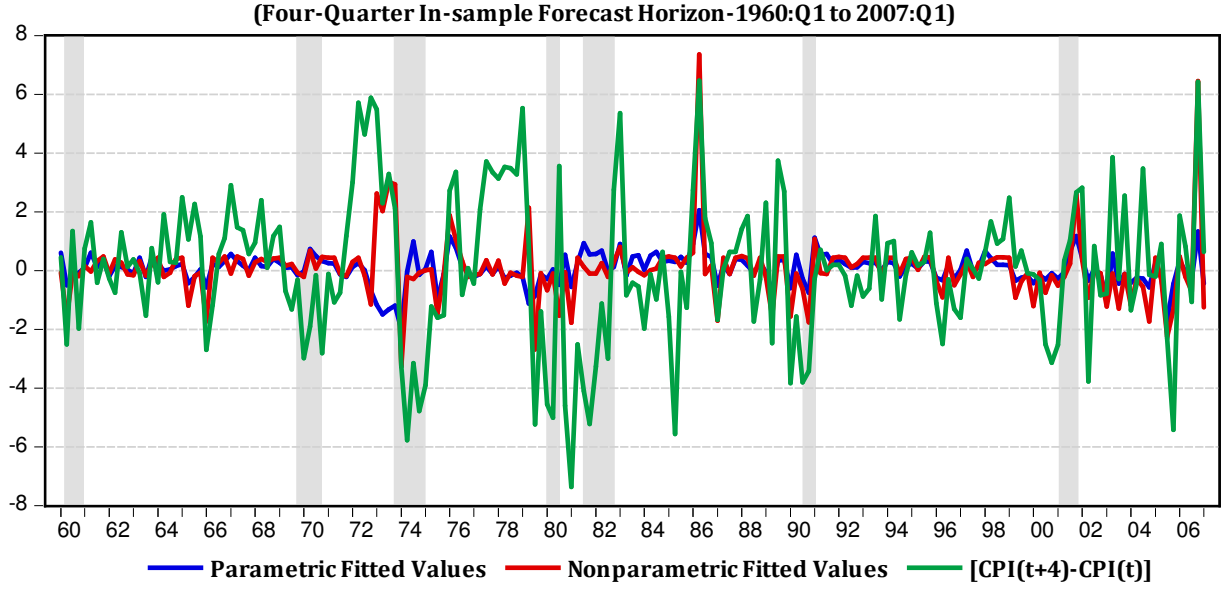

Graph 3A: Fitted Values using PCE--Vintage 2008:Q2

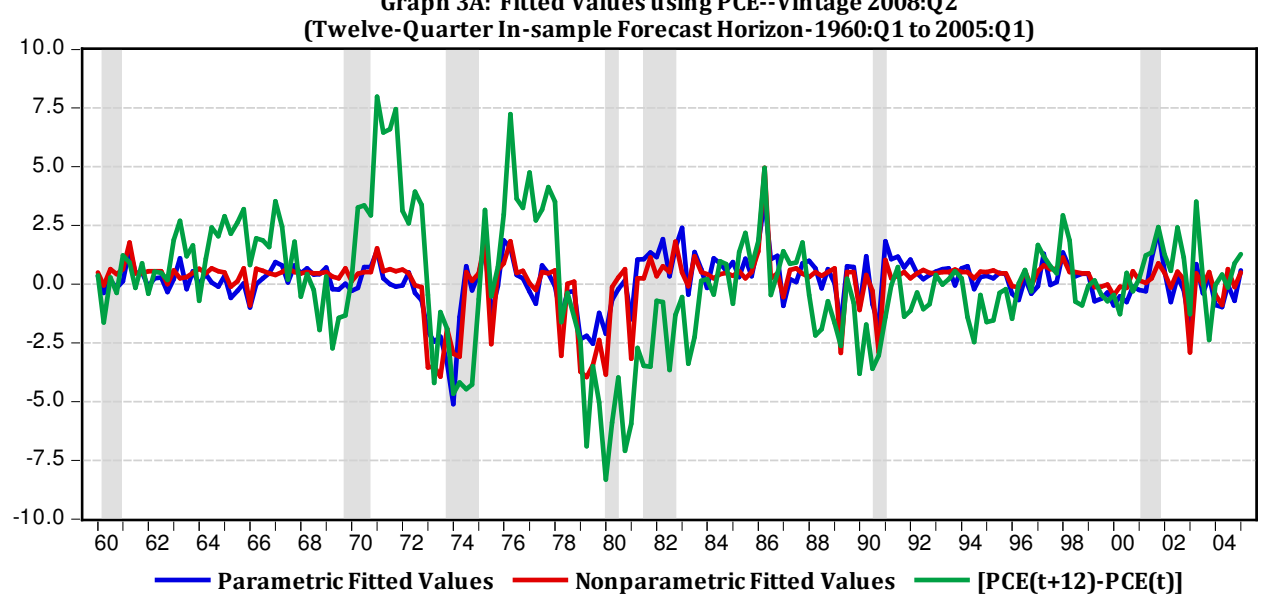

Graph 3B: Fitted Values using CPI--Vintage 2008:Q2

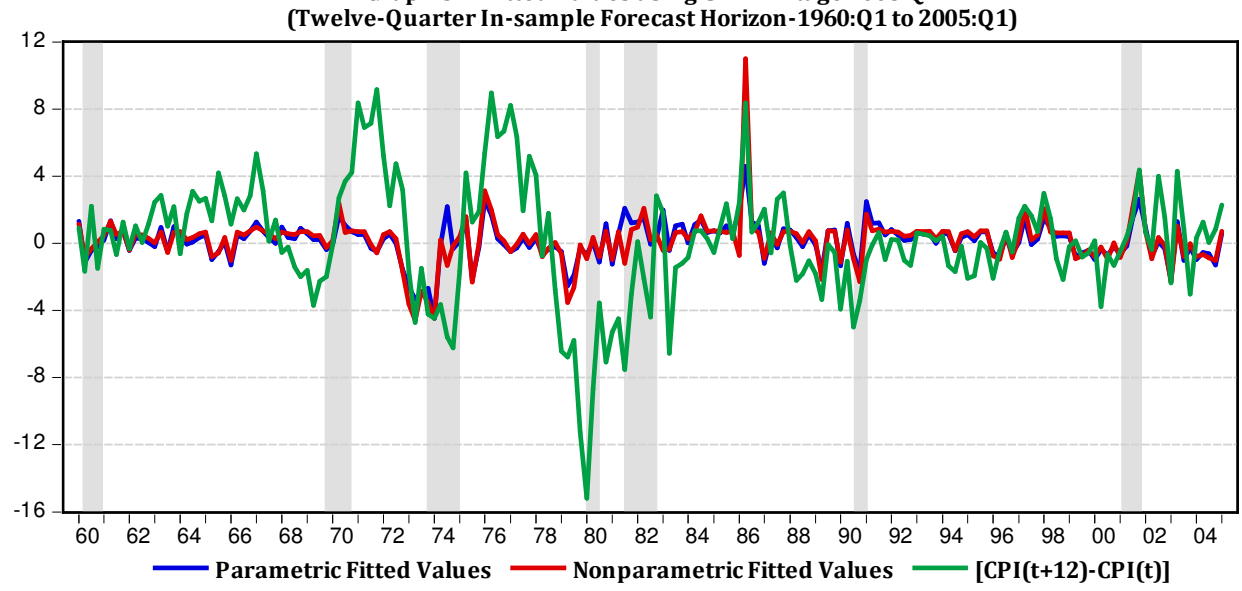



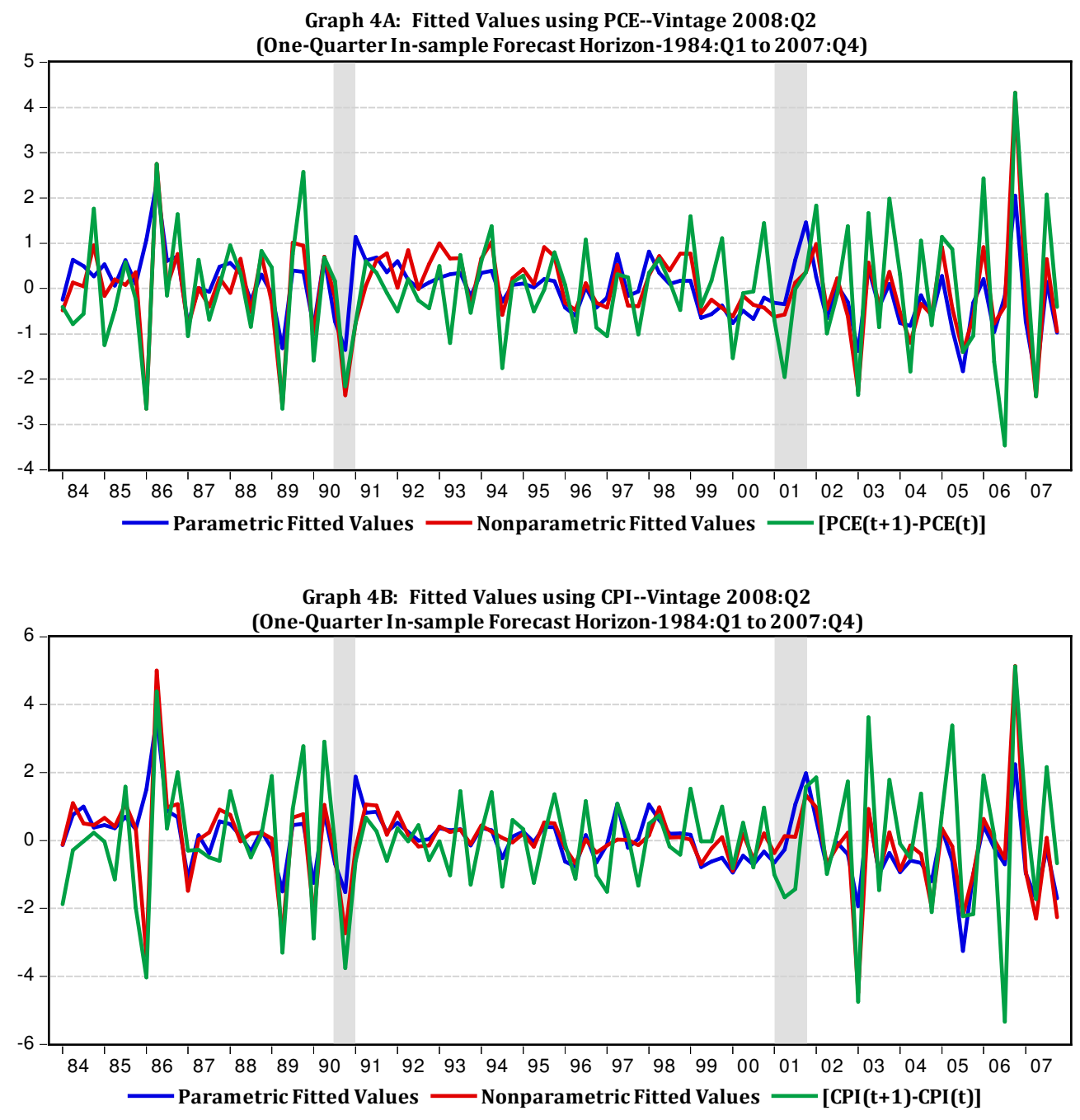
Graph 5A: Fitted Values using PCE--Vintage 2008:Q2

(Four-Quarter In-sample Forecast Horizon-1984:Q1 to 2007:Q1)

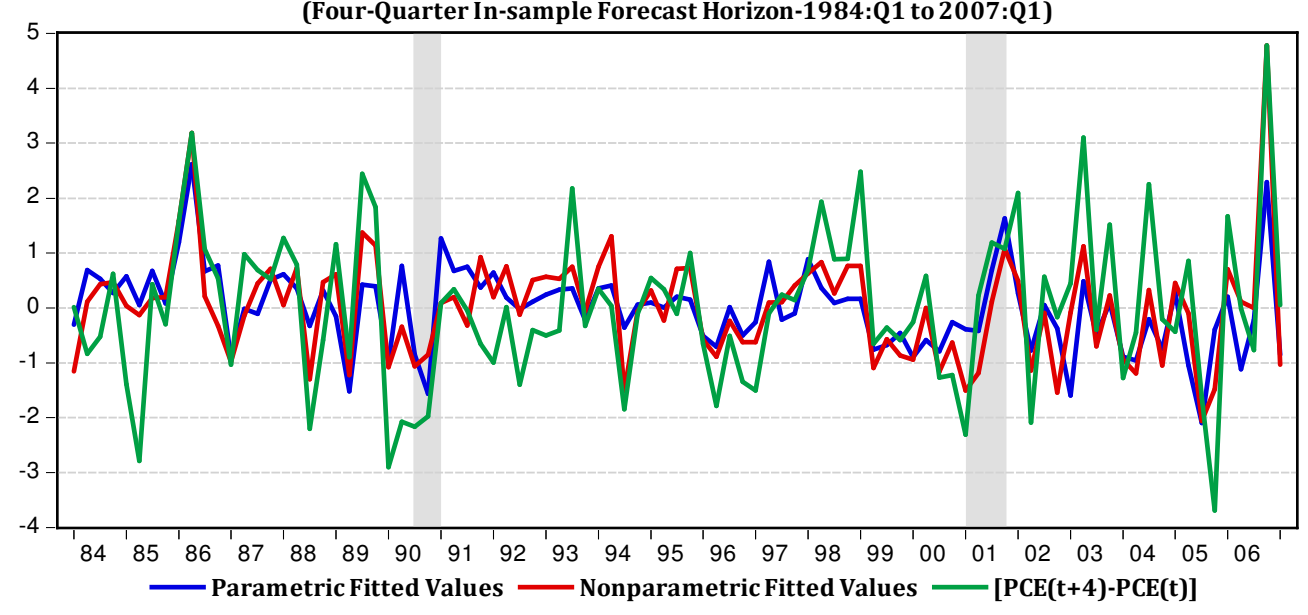

Graph 5B: Fitted Values using CPI--Vintage 2008:Q2

(Four-Quarter In-sample Forecast Horizon-1984:Q1 to 2007:Q1)

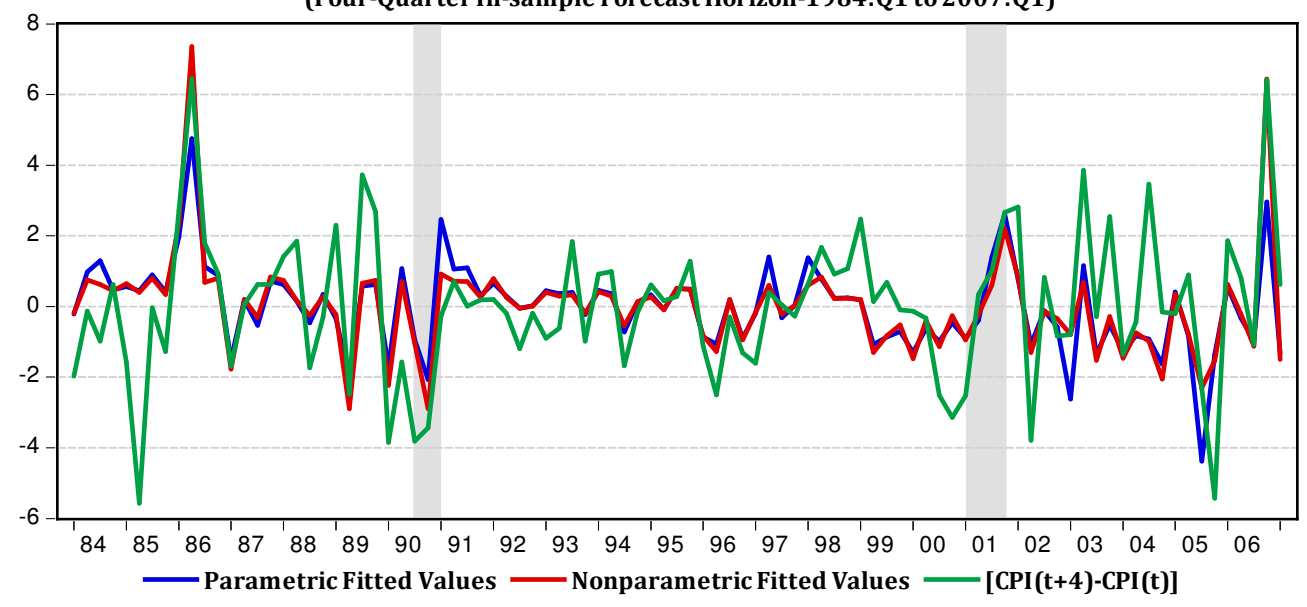




\section{Legends and Tables}

Legend 1

\begin{tabular}{|c|c|c|}
\hline \multicolumn{3}{|c|}{ Regression Model--Equation (6) } \\
\hline Regression & Dependent Variable & Independent Variable \\
\hline REG A & $\left(\mathrm{PCE}_{t+h}-\mathrm{PCE}_{t}\right)$ & $\left(\mathrm{PCE}_{t}^{\text {core }}-\mathrm{PCE}_{t}\right)$ \\
\hline REG B & $\left(\mathrm{CPI}_{t+h}-\mathrm{CPI}_{t}\right)$ & $\left(\mathrm{CPI}_{t}^{\text {core }}-\mathrm{CPI}_{t}\right)$ \\
\hline
\end{tabular}

Legend 2

\begin{tabular}{|c|c|c|}
\hline Regression Model A & Regression Model B & Forecast Horizon: h \\
\hline REG A:h $h_{1}$ & REG $B: h_{1}$ & 1 quarter \\
\hline REG A:h $h_{2}$ & REG $B: h_{2}$ & 2 quarters \\
\hline REG A: $h_{3}$ & REG $B: h_{3}$ & 4 quarters \\
\hline REG A: $h_{4}$ & REG $: h_{4}$ & 8 quarters \\
\hline REG A: $h_{5}$ & REG $B: h_{5}$ & 12 quarters \\
\hline
\end{tabular}

Legend 3

\begin{tabular}{|c|c|c|c|c|}
\hline Est. Regression Coefficients & $\begin{array}{c}\text { Parametric } \\
\text { (REG A) }\end{array}$ & $\begin{array}{c}\text { Parametric } \\
\text { (REG B) }\end{array}$ & $\begin{array}{c}\text { Global Nonparametric } \\
\text { (REG A) }\end{array}$ & $\begin{array}{c}\text { Global Nonparametric } \\
\text { (REG B) }\end{array}$ \\
\hline Vertical Intercept & $\mathbf{a}_{\mathrm{AP}}$ & $\mathbf{a}_{\mathrm{BP}}$ & $\mathbf{a}_{\mathrm{AG}}$ & $\mathbf{a}_{\mathrm{BG}}$ \\
\hline Slope Coefficient & $\mathbf{b}_{\mathrm{AP}}$ & $\mathbf{b}_{\mathrm{BP}}$ & $\mathbf{b}_{\mathrm{AG}}$ & $\mathbf{b}_{\mathrm{BG}}$ \\
\hline
\end{tabular}

Legend 4

\begin{tabular}{|c|c|c|c|}
\hline & \multicolumn{2}{|c|}{ Data Samples } & \\
\hline Forecast Horizon: $\mathbf{h}$ & 1960:Q1-2008:Q1 & 1984:Q1-2008:Q1 & Ending Data Period \\
\hline $\mathrm{h}_{1}$ & 192 & 96 & 2007:Q4 \\
\hline $\mathrm{h}_{2}$ & 191 & 95 & 2007:Q3 \\
\hline $\mathrm{h}_{3}$ & 189 & 93 & 2007:Q1 \\
\hline $\mathrm{h}_{4}$ & 185 & 89 & 2006:Q1 \\
\hline $\mathrm{h}_{5}$ & 181 & 85 & 2005:Q1 \\
\hline
\end{tabular}

Table 1A: REG A -Average Regression Results (Starting in1960:Q1)

\begin{tabular}{|c|c|c|c|c|c|c|c|c|c|c|c|c|c|c|c|c|}
\hline \multirow[b]{2}{*}{$\mathbf{h}_{\mathrm{m}}$} & \multicolumn{8}{|c|}{ PARAMETRIC REGRESSION } & \multicolumn{8}{|c|}{ GLOBAL NONPARAMETRIC REGRESSION } \\
\hline & $\mathbf{a}_{\mathrm{AP}}$ & S.D. & T-Stat & PV & $\mathbf{b}_{\mathrm{AP}}$ & S.D. & T-Stat & PV & $a_{A G}$ & S.D. & T-Stat & PV & $\mathbf{b}_{\mathrm{AG}}$ & S.D. & T-Stat & PV \\
\hline$h_{1}=1 Q$ & 0.025 & 0.08 & 0.31 & 0.76 & 0.220 & 0.14 & 1.59 & 0.12 & -0.047 & 0.07 & -0.57 & 0.33 & 0.360 & 0.07 & 4.94 & 0.00 \\
\hline$h_{2}=2 Q$ & 0.025 & 0.12 & 0.21 & 0.83 & 0.237 & 0.19 & 1.28 & 0.23 & -0.248 & 0.11 & -2.28 & 0.14 & 0.418 & 0.09 & 4.60 & 0.00 \\
\hline$h_{3}=4 Q$ & 0.029 & 0.22 & 0.13 & 0.89 & 0.272 & 0.25 & 1.09 & 0.28 & -0.039 & 0.19 & -0.23 & 0.61 & 0.395 & 0.15 & 2.50 & 0.02 \\
\hline$h_{4}=8 Q$ & 0.101 & 0.39 & 0.26 & 0.79 & 0.814 & 0.21 & 3.87 & 0.00 & 0.488 & 0.35 & 1.38 & 0.21 & 0.465 & 0.17 & 2.70 & 0.07 \\
\hline$h_{5}=12 Q$ & 0.134 & 0.51 & 0.27 & 0.79 & 1.067 & 0.25 & 4.28 & 0.00 & 0.517 & 0.45 & 1.15 & 0.30 & 0.660 & 0.17 & 4.01 & 0.00 \\
\hline
\end{tabular}

Table 1B: REG B-Average Regression Results (Starting in 1960:Q1)

\begin{tabular}{|c|c|c|c|c|c|c|c|c|c|c|c|c|c|c|c|c|}
\hline \multirow[b]{2}{*}{$\underline{\mathbf{h}_{\mathbf{m}}}$} & \multicolumn{8}{|c|}{ PARAMETRIC REGRESSION } & \multicolumn{8}{|c|}{ GLOBAL NONPARAMETRIC REGRESSION } \\
\hline & $\mathbf{a}_{\mathrm{BP}}$ & S.D. & T-Stat & PV & $\mathbf{b}_{\mathrm{BP}}$ & S.D. & T-Stat & PV & $a_{A G}$ & S.D. & T-Stat & PV & $\mathbf{b}_{\mathrm{AG}}$ & S.D. & T-Stat & PV \\
\hline$h_{1}=1 Q$ & 0.009 & 0.12 & 0.07 & 0.92 & 0.264 & 0.13 & 2.11 & 0.05 & -0.171 & 0.11 & -1.55 & 0.22 & 0.456 & 0.09 & 5.10 & 0.00 \\
\hline$h_{2}=2 Q$ & 0.012 & 0.17 & 0.07 & 0.93 & 0.200 & 0.19 & 1.08 & 0.31 & -0.375 & 0.16 & -2.44 & 0.05 & 0.448 & 0.11 & 3.94 & 0.00 \\
\hline$h_{3}=4 Q$ & 0.022 & 0.31 & 0.07 & 0.94 & 0.257 & 0.26 & 1.01 & 0.33 & -0.054 & 0.27 & -0.20 & 0.78 & 0.215 & 0.13 & 1.67 & 0.31 \\
\hline$h_{4}=8 Q$ & 0.053 & 0.54 & 0.10 & 0.92 & 0.621 & 0.17 & 3.58 & 0.00 & 0.345 & 0.50 & 0.70 & 0.50 & 0.478 & 0.16 & 3.06 & 0.06 \\
\hline$h_{5}=12 Q$ & 0.072 & 0.66 & 0.11 & 0.91 & 0.834 & 0.18 & 4.59 & 0.00 & 0.101 & 0.63 & 0.15 & 0.81 & 0.894 & 0.16 & 5.59 & 0.00 \\
\hline
\end{tabular}




\begin{tabular}{|c|c|c|c|c|c|c|c|c|c|c|c|c|c|c|c|c|}
\hline \multirow[b]{2}{*}{$\mathbf{h}_{\mathbf{m}}$} & \multicolumn{8}{|c|}{ PARAMETRIC REGRESSION } & \multicolumn{8}{|c|}{ GLOBAL NONPARAMETRIC REGRESSION } \\
\hline & $\mathbf{a}_{1 \mathrm{AP}}$ & S.D. & T-Stat & PV & $\mathbf{b}_{1 \mathrm{AP}}$ & S.D. & T-Stat & PV & $1 \mathrm{AG}$ & S.D. & T-Stat & PV & $\mathbf{b}_{1 \mathrm{AG}}$ & S.D. & T-Stat & PV \\
\hline$h_{1}=1 Q$ & -0.123 & 0.10 & -1.13 & 0.35 & 0.672 & 0.13 & 5.07 & 0.00 & -0.105 & 0.09 & -1.60 & 0.19 & 0.734 & 0.09 & 9.76 & 0.00 \\
\hline$h_{2}=2 Q$ & -0.174 & 0.14 & -1.16 & 0.32 & 0.828 & 0.13 & 6.31 & 0.00 & -1.601 & 0.12 & -18.80 & 0.07 & -0.145 & 0.13 & -8.28 & 0.00 \\
\hline$h_{3}=4 Q$ & -0.242 & 0.18 & -1.30 & 0.28 & 0.931 & 0.14 & 6.55 & 0.00 & -1.854 & 0.17 & -18.28 & 0.24 & -0.397 & 0.10 & -12.88 & 0.09 \\
\hline$h_{4}=8 Q$ & -0.385 & 0.24 & -1.61 & 0.21 & 1.024 & 0.19 & 5.40 & 0.00 & 1.308 & 0.21 & 11.05 & 0.42 & 1.392 & 0.11 & 17.97 & 0.16 \\
\hline$h_{5}=12 Q$ & -0.446 & 0.34 & -1.29 & 0.27 & 1.052 & 0.19 & 5.67 & 0.00 & -0.023 & 0.28 & 0.50 & 0.19 & 0.702 & 0.09 & 8.76 & 0.00 \\
\hline
\end{tabular}

Table 2B: REG B-Average Regression Results (Starting in 1984:Q1)

\begin{tabular}{|c|c|c|c|c|c|c|c|c|c|c|c|c|c|c|c|c|}
\hline \multirow[b]{2}{*}{$\mathbf{h}_{\mathbf{m}}$} & \multicolumn{8}{|c|}{ PARAMETRIC REGRESSION } & \multicolumn{8}{|c|}{ GLOBAL NONPARAMETRIC REGRESSION } \\
\hline & a1BP & S.D. & T-Stat & PV & $\mathbf{b}_{1 \mathrm{BP}}$ & S.D. & T-Stat & PV & a1BG & S.D. & T-Stat & PV & $\mathbf{b}_{1 \mathrm{BG}}$ & S.D. & T-Stat & PV \\
\hline$h_{1}=1 Q$ & -0.217 & 0.14 & -1.53 & 0.21 & 0.654 & 0.14 & 4.72 & 0.00 & -0.155 & 0.12 & -1.29 & 0.30 & 0.912 & 0.07 & 12.49 & 0.00 \\
\hline$h_{2}=2 Q$ & -0.293 & 0.20 & -1.41 & 0.22 & 0.84 & 0.12 & 6.94 & 0.00 & 0.004 & 0.18 & -0.16 & 0.05 & 1.209 & 0.08 & 15.19 & 0.00 \\
\hline$h_{3}=4 Q$ & -0.388 & 0.26 & -1.48 & 0.21 & 1.003 & 0.15 & 6.56 & 0.00 & -0.147 & 0.23 & -0.69 & 0.45 & 0.712 & 0.09 & 7.57 & 0.00 \\
\hline$h_{4}=8 Q$ & -0.494 & 0.33 & -1.49 & 0.19 & 1.039 & 0.15 & 7.22 & 0.00 & -0.188 & 0.30 & -0.68 & 0.56 & 0.757 & 0.10 & 7.66 & 0.00 \\
\hline$h_{5}=12 Q$ & -0.484 & 0.35 & -1.38 & 0.22 & 1.114 & 0.15 & 7.46 & 0.00 & -0.661 & 0.33 & -2.17 & 0.17 & 1.151 & 0.13 & 10.28 & 0.00 \\
\hline
\end{tabular}

\begin{tabular}{|c|c|c|c|c|c|c|}
\hline \multirow{2}{*}{} & \multicolumn{3}{|c|}{ Table 3: Average of Adjusted R-Squared Term (Starting in 1960:Q1) } \\
\cline { 2 - 7 } & \multicolumn{3}{|c|}{ REG A } & \multicolumn{3}{c|}{ REG B } \\
\hline $\mathbf{h}_{\mathbf{m}}$ & Parametrics & $\begin{array}{c}\text { Global/Local } \\
\text { Nonparametrics }\end{array}$ & $\begin{array}{c}\text { \% } \\
\text { Change }\end{array}$ & Parametrics & $\begin{array}{c}\text { Global/Local } \\
\text { Nonparametrics }\end{array}$ & $\begin{array}{c}\text { \% } \\
\text { Change }\end{array}$ \\
\hline $\mathbf{h}_{\mathbf{1}}=\mathbf{1 Q}$ & $\mathbf{0 . 0 2 9}$ & 0.254 & $776 \%$ & 0.038 & 0.190 & $400 \%$ \\
$\mathbf{h}_{\mathbf{2}}=\mathbf{2 Q}$ & $\mathbf{0 . 0 2 3}$ & 0.229 & $896 \%$ & 0.012 & 0.155 & $1,192 \%$ \\
$\mathbf{h}_{\mathbf{3}}=\mathbf{4 Q}$ & $\mathbf{0 . 0 1 7}$ & 0.243 & $1,329 \%$ & 0.014 & 0.184 & $1,214 \%$ \\
$\mathbf{h}_{\mathbf{4}}=\mathbf{8 Q}$ & $\mathbf{0 . 1 1 0}$ & 0.221 & $101 \%$ & 0.054 & 0.143 & $165 \%$ \\
$\mathbf{h}_{\mathbf{5}}=\mathbf{1 2 Q}$ & $\mathbf{0 . 1 6 5}$ & 0.266 & $61 \%$ & 0.086 & 0.160 & $86 \%$ \\
\hline
\end{tabular}

\begin{tabular}{|c|c|c|c|c|c|c|}
\hline \multirow{2}{*}{} & \multicolumn{3}{|c|}{ Table 4: Average of Adjusted R-Squared Term (Starting in 1984:Q1) } \\
\cline { 2 - 7 } & \multicolumn{3}{|c|}{ REG A } & \multicolumn{3}{c|}{ REG B } \\
\hline $\mathbf{h}_{\mathbf{m}}$ & Parametrics & $\begin{array}{c}\text { Global/Local } \\
\text { Nonparametrics }\end{array}$ & $\begin{array}{c}\text { \% } \\
\text { Change }\end{array}$ & Parametrics & $\begin{array}{c}\text { Global/Local } \\
\text { Nonparametrics }\end{array}$ & $\begin{array}{c}\text { \% } \\
\text { Change }\end{array}$ \\
\hline $\mathbf{h}_{\mathbf{1}}=\mathbf{1 Q}$ & $\mathbf{0 . 2 3 0}$ & 0.448 & $95 \%$ & 0.253 & 0.568 & $125 \%$ \\
$\mathbf{h}_{\mathbf{2}}=\mathbf{2 Q}$ & $\mathbf{0 . 2 6 8}$ & 0.394 & $47 \%$ & 0.321 & 0.416 & $30 \%$ \\
$\mathbf{h}_{\mathbf{3}}=\mathbf{4 Q}$ & $\mathbf{0 . 2 8 2}$ & 0.397 & $41 \%$ & 0.368 & 0.464 & $26 \%$ \\
$\mathbf{h}_{\mathbf{4}}=\mathbf{8 Q}$ & $\mathbf{0 . 3 0 0}$ & 0.433 & $44 \%$ & 0.346 & 0.450 & $30 \%$ \\
$\mathbf{h}_{\mathbf{5}}=\mathbf{1 2 Q}$ & $\mathbf{0 . 2 8 9}$ & 0.463 & $60 \%$ & 0.427 & 0.574 & $34 \%$ \\
\hline
\end{tabular}




\begin{tabular}{|c|c|c|c|c|c|c|}
\hline & \multicolumn{6}{|c|}{ Table 5A: REG A-Summary of Tests for Unbiasedness } \\
\hline & \multicolumn{2}{|c|}{ Parametrics } & \multicolumn{2}{|c|}{ Global Nonparametrics } & \multicolumn{2}{|c|}{ Local Nonparametrics } \\
\hline $\mathbf{h}_{\mathrm{m}}$ & 1960:Q1 & 1984:Q1 & 1960:Q1 & 1984:Q1 & 1960:Q1 & 1984:Q1 \\
\hline $1 Q$ & $\begin{array}{l}\text { Biased } \\
\left(\beta_{\text {ave }}=\right. \\
0.220)\end{array}$ & $\begin{array}{c}\text { Unbiased: } \\
\text { After } \\
\text { V_2007:Q1 } \\
\left(\beta_{\text {ave }}=0.672\right)\end{array}$ & $\begin{array}{l}\text { Biased } \\
\left(\beta_{\text {ave }}=\right. \\
0.360)\end{array}$ & $\begin{array}{c}\text { Biased } \\
\left(\beta_{\text {ave }}=0.734\right)\end{array}$ & Biased & Biased \\
\hline $2 Q$ & $\begin{array}{l}\text { Biased } \\
\left(\beta_{\text {ave }}=\right. \\
0.237) \\
\end{array}$ & $\begin{array}{c}\text { Unbiased: } \\
\text { All Vintages } \\
\left(\beta_{\text {ave }}=0.828\right)\end{array}$ & $\begin{array}{c}\text { Biased } \\
\left(\beta_{\text {ave }}=0.418\right)\end{array}$ & $\begin{array}{c}\text { Biased } \\
\left(\beta_{\mathrm{ave}}=-0.145\right)\end{array}$ & Biased & $\begin{array}{c}\text { Biaseda } \\
\text { (some } \\
\text { exceptions) } \\
\end{array}$ \\
\hline $4 Q$ & $\begin{array}{c}\text { Biased } \\
\left(\beta_{\text {ave }}=0.272\right)\end{array}$ & $\begin{array}{c}\text { Unbiased: } \\
\text { All Vintages } \\
\left(\beta_{\text {ave }}=0.931\right)\end{array}$ & $\begin{array}{l}\text { Biased } \\
\quad\left(\beta_{\text {ave }}\right. \\
=0.395)\end{array}$ & $\begin{array}{c}\text { Biased } \\
\left(\beta_{\text {ave }}=-\right. \\
0.397)\end{array}$ & Biased & $\begin{array}{c}\text { Biased } \\
\text { V_2000:Q1 } \\
\text { \& after } \\
\text { V_2002:Q4 } \\
\end{array}$ \\
\hline $\mathbf{8 Q}$ & $\begin{array}{c}\text { Unbiased } \\
\left(\beta_{\text {ave }}=0.814\right)\end{array}$ & $\begin{array}{c}\text { Unbiased: } \\
\text { After } \\
\text { V_2003:Q3 } \\
\left(\beta_{\text {ave }}=1.024\right)\end{array}$ & $\begin{array}{c}\text { Biased } \\
\left(\beta_{\text {ave }}=0.465\right)\end{array}$ & $\begin{array}{c}\text { Biased } \\
\left(\beta_{\text {ave }}=1.392\right)\end{array}$ & $\begin{array}{c}\text { Biased } \\
\text { except } \\
\text { V_1999:Q4 }\end{array}$ & $\begin{array}{c}\text { Biased } \\
\text { except } \\
\text { V_1999:Q4 }\end{array}$ \\
\hline $12 Q$ & $\begin{array}{c}\text { Unbiased } \\
\left(\beta_{\mathrm{ave}}=1.067\right)\end{array}$ & $\begin{array}{c}\text { Unbiased: } \\
\text { After } \\
\text { V_2003:Q4 } \\
\left(\beta_{\text {ave }}=1.052\right)\end{array}$ & $\begin{array}{c}\text { Biased } \\
\left(\beta_{\text {ave }}\right. \\
=0.660)\end{array}$ & $\begin{array}{c}\text { Biased } \\
\left(\beta_{\text {ave }}=0.702\right)\end{array}$ & $\begin{array}{c}\text { Biased } \\
\text { not valid } \\
\text { in } \\
\text { V_1999:Q4 }\end{array}$ & Biased \\
\hline
\end{tabular}

\begin{tabular}{|c|c|c|c|c|c|c|}
\hline & \multicolumn{6}{|c|}{ Table 5B: REG B-Summary of Tests for Unbiasedness } \\
\hline & \multicolumn{2}{|c|}{ Parametrics } & \multicolumn{2}{|c|}{ Global Nonparametrics } & \multicolumn{2}{|c|}{ Local Nonparametrics } \\
\hline $\mathbf{h}_{\mathbf{m}}$ & 1960:Q1 & 1984:Q1 & 1960:Q1 & 1984:Q1 & 1960:Q1 & 1984:Q1 \\
\hline $1 Q$ & $\begin{array}{c}\text { Biased } \\
\left(\beta_{\text {ave }} 0.264\right)\end{array}$ & $\begin{array}{c}\text { Biased } \\
\left(\beta_{\text {ave }}=0.654\right)\end{array}$ & $\begin{array}{c}\text { Biased } \\
\left(\beta_{\text {ave }}=0.456\right)\end{array}$ & $\begin{array}{c}\text { Biased } \\
\left(\beta_{\text {ave }}=0.912\right)\end{array}$ & Biased & $\begin{array}{c}\text { Biased } \\
\text { except } \\
\text { V_2007:Q1 } \\
\text { to V_2007:Q2 }\end{array}$ \\
\hline $2 Q$ & $\begin{array}{c}\text { Biased } \\
\left(\beta_{\text {ave }} 0.200\right)\end{array}$ & $\begin{array}{c}\text { Unbiased }^{b}: \\
\text { After } \\
\text { V_2000:Q2 } \\
\left(\beta_{\text {ave }}=0.844\right)\end{array}$ & $\begin{array}{c}\text { Biased } \\
\left(\beta_{\text {ave }}=0.448\right)\end{array}$ & $\begin{array}{c}\text { Biased } \\
\left(\beta_{\mathrm{ave}}=1.209\right)\end{array}$ & Biased & Biased \\
\hline $4 Q$ & $\begin{array}{c}\text { Biased } \\
\left(\beta_{\text {ave }} 0.257\right)\end{array}$ & $\begin{array}{c}\text { Unbiased }^{\mathrm{b}}: \\
\text { After } \\
\text { V_2000:Q2 } \\
\left(\beta_{\text {ave }}=1.003\right)\end{array}$ & $\begin{array}{c}\text { Biased } \\
\left(\beta_{\text {ave }}=0.215\right)\end{array}$ & $\begin{array}{c}\text { Biased } \\
\left(\beta_{\text {ave }}=0.712\right)\end{array}$ & Biased & Biased \\
\hline $8 Q$ & $\begin{array}{c}\text { Unbiased } \\
\text { All Vintages } \\
\left(\beta_{\text {ave }}=0.621\right)\end{array}$ & $\begin{array}{c}\text { Unbiased }^{b}: \\
\text { After } \\
\text { V_2000:Q2 } \\
\left(\beta_{\text {ave }}=1.039\right)\end{array}$ & $\begin{array}{c}\text { Biased } \\
\left(\beta_{\text {ave }}=0.478\right)\end{array}$ & $\begin{array}{c}\text { Biased } \\
\left(\beta_{\mathrm{ave}}=0.757\right)\end{array}$ & Biased & $\begin{array}{c}\text { Unbiased for } \\
\text { V_2001:Q1, } \\
\text { V_2001:Q3 to } \\
\text { V_2001:Q4, \& after } \\
\text { V_2006:Q2 }\end{array}$ \\
\hline $12 Q$ & $\begin{array}{c}\text { Unbiased } \\
\text { All Vintages } \\
\left(\beta_{\text {ave }} 0.834\right)\end{array}$ & $\begin{array}{c}\text { Unbiased }^{\mathrm{b}} \text { : } \\
\text { After } \\
\text { V_2000:Q1 } \\
\left(\beta_{\text {ave }}=1.114\right)\end{array}$ & $\begin{array}{c}\text { Biased } \\
\left(\beta_{\mathrm{ave}}=0.894\right)\end{array}$ & $\begin{array}{c}\text { Biased } \\
\left(\beta_{\mathrm{ave}}=1.151\right)\end{array}$ & $\begin{array}{c}\begin{array}{c}\text { Unbiased } \\
\text { except }\end{array} \\
\text { V_2005:Q3 } \\
\text { to } \\
\text { V_2006:Q1 }\end{array}$ & Biased \\
\hline
\end{tabular}

a In the local nonparametric model, there is sporadic unbiasedness during the following vintages for the following in-sample forecast horizon: $h_{2}$ : V_1996:Q1 to V_1997:Q1, V_1999:Q4, and V_2000:Q2 to V_2002:Q2.

b Regarding the parametric model for the second sample period, the null of unbiasedness is rejected for the following vintages at the 5\% significance level: $h_{2}: V \_1998: Q 2$ to $V \_2000: Q 1$ and V_2002:Q2, h3:V_1997:Q4 to V_2000:Q1, h4: V_1997:Q3 to V_2000:Q2, V_2002:Q2, and V_2003:Q3 to V_2004:Q2 h $_{5}$ : V_1997:Q3 to V_2000:Q2, V_2002:Q2 to V_2002:Q3, and V_2004:Q1. 


\begin{tabular}{|c|c|c|c|c|c|c|c|c|c|c|}
\hline \multirow[b]{2}{*}{ Vintage } & \multicolumn{2}{|c|}{ REG A: h1 } & \multicolumn{2}{|c|}{ REG A: h2 } & \multicolumn{2}{|c|}{ REG A: h3 } & \multicolumn{2}{|c|}{ REG A: h4 } & \multicolumn{2}{|c|}{ REG A: h5 } \\
\hline & LR-Stat & P-Value & LR-Stat & P-Value & LR-Stat & P-Value & LR-Stat & P-Value & LR-Stat & P-Value \\
\hline 1996:Q1 & 144.12 & 0.00 & 95.88 & 0.00 & 73.66 & 0.00 & 29.60 & 0.00 & 21.15 & 0.02 \\
\hline 1996:Q2 & 143.68 & 0.00 & 632 & 0.00 & 74.11 & 0.00 & 30.02 & .00 & & 0.02 \\
\hline 1996:Q3 & 3.08 & 0.00 & 96.52 & 0.00 & 74.14 & 0.00 & 30.11 & 0.00 & 20.91 & 0.02 \\
\hline 1996:Q4 & 141.63 & 0.00 & 96.89 & 0.00 & 74.65 & 0.00 & 29.28 & 0.00 & 20.99 & 0.02 \\
\hline 1997:Q1 & 141.67 & 0.00 & 97.54 & 0.00 & 75.00 & 0.00 & 29.58 & 0.00 & 21.11 & 0.02 \\
\hline 1997:Q2 & 127.00 & 0.00 & 103.78 & 0.00 & 100.67 & 0.00 & 34.53 & 0.00 & 23.75 & 0.01 \\
\hline 1997:Q3 & 129.45 & 0.00 & 103.05 & 0.00 & 98.38 & 0.00 & 35.04 & 0.00 & 23.45 & 0.01 \\
\hline 1997:Q4 & 130.38 & 0.00 & 103.90 & 0.00 & 98.90 & 0.00 & 35.00 & 0.00 & 22.78 & 0.01 \\
\hline 1998:Q1 & 131.18 & 0.00 & 104.65 & 0.00 & & 0.00 & & 0.00 & 22.25 & 0.01 \\
\hline 1998:Q2 & 132.08 & 0.00 & 1 & 0.00 & & 0.00 & 01 & 0.00 & 21.81 & 0.02 \\
\hline 1998:Q3 & 131.40 & 0.00 & 104.17 & 0.00 & 100.56 & 0.00 & 32.73 & 0.00 & 21.15 & 0.02 \\
\hline 1998:Q4 & 132.52 & 0.00 & 104.38 & 0.00 & & 0.00 & & 0.00 & & 0.02 \\
\hline 1999:Q1 & $\mid 133.24$ & 0.00 & 104 & 0.00 & 10 & 0.00 & 45 & 0.00 & 20.77 & 0.02 \\
\hline 1999:Q2 & 134.09 & 0.00 & 105.58 & 0.00 & 101.45 & 0.00 & 32.11 & 0.00 & 20.68 & 0.02 \\
\hline 1999:Q3 & 133.34 & 0.00 & 105.53 & 0.00 & 101.52 & 0.00 & 31.45 & 0.00 & 21.04 & 0.02 \\
\hline 1999:Q4 & 24.19 & 0.01 & 2. & 0.01 & 12.72 & 0.25 & & 0.93 & -0.80 & -1.00 \\
\hline $000: Q 1$ & 181.31 & 0.00 & 139.35 & 0.00 & 138.56 & 0.00 & 47.95 & 0.00 & 54.73 & 0.00 \\
\hline 000:Q2 & 130.14 & 0.00 & 100.60 & 0.00 & 80.32 & 0.00 & 24.40 & 0.01 & 22.92 & 0.01 \\
\hline 2000:Q3 & 129.92 & 0.00 & 101 & & & 0.00 & & .01 & 23.83 & 0.01 \\
\hline 2000:Q4 & 130.28 & 0.00 & 10 & 0.00 & 82 & 0.00 & & 0.01 & 25 & 0.01 \\
\hline 001:Q1 & 131.18 & 0.00 & 102.09 & 0.00 & 82 & 0.00 & 8 & 0.01 & 41 & 0.01 \\
\hline 2001:Q2 & 131.10 & 0.00 & 102 & & & 0.00 & 24 & 0.01 & 23 & .01 \\
\hline 2001:Q3 & 129.51 & 0.00 & 1 & 0.00 & & 0.00 & & 0.00 & & 0.01 \\
\hline 2001:Q4 & 127.89 & 0.00 & 100.75 & 0.00 & & 0.00 & 4 & 0.01 & 24.14 & 0.01 \\
\hline 2002:Q1 & 128.37 & 0.00 & 101.82 & 0.00 & 83. & 0.00 & 25.48 & 0.01 & 23.85 & 0.01 \\
\hline 2002:Q2 & 129.00 & 0.00 & 102 & & & 0.00 & 31 & 0.01 & 23.53 & .01 \\
\hline 2002:Q3 & 131.83 & 0.00 & & & & 0.00 & & 0.00 & & 0.01 \\
\hline 2002:Q4 & 131.76 & 0.00 & 104.01 & 0.00 & 83.48 & 0.00 & 26.28 & 0.00 & 24.33 & 0.01 \\
\hline 2003:Q1 & 132.18 & 0.00 & $\mid 104.67$ & 0 & 84 & 0.00 & 26.23 & 0.00 & 24 & 0.01 \\
\hline 2003:Q2 & 132.38 & 0.00 & & 0 & & 0.00 & & 0.00 & & 0.01 \\
\hline 2003:Q3 & 131.92 & 0.00 & 105.23 & 0.00 & 8 & 0.00 & 26.42 & 0.00 & 24.89 & 0.01 \\
\hline 2003:Q4 & 131.13 & 0.00 & 105.33 & 0.00 & 85. & 0.00 & 25.49 & 0.01 & 25.41 & 0.01 \\
\hline 2004:Q1 & 133.28 & 0.00 & 103 & 0.00 & 82 & 0.00 & 5 & 0.01 & 25.35 & 0.01 \\
\hline 2004:Q2 & 132.66 & 0.00 & & & & 0.00 & & 0.01 & & 0.00 \\
\hline 2004:Q3 & 134.44 & 0.00 & 103.61 & & & 0.00 & 1 & 0.01 & 26 & 0.00 \\
\hline 2004:Q4 & 133.57 & 0.00 & 103 & 0 & 82 & 0.00 & 5 & 0.01 & 26.02 & 0.00 \\
\hline 2005:Q1 & 133.89 & 0.00 & 103.71 & 0.00 & 82.55 & 0.00 & 23.76 & 0.01 & 25.42 & 0.01 \\
\hline 2005:Q2 & 134.34 & 0.00 & 103.56 & & 82.78 & 0.00 & 22.56 & 0.02 & 25.30 & 0.01 \\
\hline 2005:Q3 & 131.17 & 0.00 & 102.55 & 0.00 & 84 & 0.00 & 23.38 & 0.01 & 25.85 & 0.00 \\
\hline 2005:Q4 & 131.40 & 0.00 & 102.49 & 0.00 & 83.92 & 0.00 & 23.93 & 0.01 & 26.24 & 0.00 \\
\hline 2006:Q1 & 130.85 & 0.00 & 102.43 & 0.00 & 8 & 0.00 & 24 & 0.01 & 26.64 & 0.00 \\
\hline 2006:Q2 & 132.22 & 0.00 & 98.8 & & & 0.00 & 24.00 & 0.01 & 25.82 & 0.00 \\
\hline 2006:Q3 & 132.17 & 0.00 & 97.87 & 0.00 & 84.79 & 0.00 & 23.71 & 0.01 & 25.56 & 0.01 \\
\hline 2006:Q4 & 131.65 & 0.00 & 98.30 & 0.00 & 78.84 & 0.00 & 24.02 & 0.01 & 25.76 & 0.01 \\
\hline 2007:Q1 & 128.27 & 0.00 & & & & 0.00 & & 0.01 & & 0.01 \\
\hline 2007:Q2 & 129.96 & 0.00 & 94.85 & & & 0.00 & 22.91 & 0.01 & & 0.01 \\
\hline 2007:Q3 & 130.85 & 0.00 & 96.91 & 0.00 & & 0.00 & 22.20 & 0.02 & 26.02 & 0.00 \\
\hline 2007:Q4 & 131.96 & 0.00 & 96.14 & 0.00 & 78.75 & 0.00 & 21.78 & 0.02 & 25.96 & 0.00 \\
\hline 2008:Q1 & 131.63 & 0.00 & 100.41 & 0.00 & 80.49 & 0.00 & 22.26 & 0.02 & 26.69 & 0.00 \\
\hline 2008:Q2 & 133.00 & 0.00 & 100.51 & 0.00 & 80.98 & 0.00 & 22.56 & 0.02 & 26.71 & 0.00 \\
\hline
\end{tabular}




\begin{tabular}{|c|c|c|c|c|c|c|c|c|c|c|}
\hline \multicolumn{5}{|c|}{ Table 6B: Fan, Zhang, and Zhang's (2001) } & \multicolumn{6}{|c|}{ LR-Statistic and P-Values (Starting in 1960:Q1) } \\
\hline & \multicolumn{2}{|c|}{ REG B: h1 } & \multicolumn{2}{|c|}{ REG B: h2 } & \multicolumn{2}{|c|}{ REG B: h3 } & \multicolumn{2}{|c|}{ REG B: h4 } & \multicolumn{2}{|c|}{ REG B: h5 } \\
\hline Vintage & LR-Stat & P-Value & LR-Stat & P-Value & LR-Stat & P-Value & LR-Stat & P-Value & LR-Stat & P-Value \\
\hline \begin{tabular}{|l|}
$1996: 01$ \\
\end{tabular} & 87.74 & 0.00 & 68.40 & 0.00 & 62.55 & 0.00 & 22.70 & 0.01 & 12.62 & 0.23 \\
\hline 1996:Q2 & 88.03 & 0.00 & 76 & 0.00 & 2.94 & 0.00 & 2.78 & 0.01 & 12.61 & 0.23 \\
\hline 1996:Q3 & 88.57 & 0.00 & 68.87 & 0.00 & 63.31 & 0.00 & 22.99 & 0.01 & 12.63 & 0.23 \\
\hline 1996:Q4 & 89.08 & 0.00 & 69.32 & 0.00 & 63.73 & 0.00 & 22.92 & 0.01 & 12.65 & 0.23 \\
\hline 1997:Q1 & 89.27 & 0.00 & 69.75 & 0.00 & 64.07 & 0.00 & 23.00 & 0.01 & 12.53 & 0.24 \\
\hline 1997:Q2 & 89.35 & 0.00 & 70.81 & 0.00 & 4.36 & 0.00 & 23.23 & 0.01 & 12.59 & 0.24 \\
\hline 1997:Q3 & 90.19 & 0.00 & 71.22 & 0.00 & 64.42 & 0.00 & 22.70 & 0.01 & 12.34 & 0.26 \\
\hline 1997:Q4 & 90.72 & 0.00 & 71.62 & 0.00 & 64.82 & 0.00 & 22.60 & 0.01 & 12.64 & 0.24 \\
\hline 1998:Q1 & 91.28 & 0.00 & 72.05 & 0.00 & 4.93 & 0.00 & 22.42 & 0.01 & 12.50 & 0.25 \\
\hline 1998:Q2 & 91.36 & 0.00 & 72.60 & 0.00 & 49 & 0.00 & 22.92 & 0.01 & 12.46 & 0.25 \\
\hline 1998:Q3 & 91.53 & 0.00 & 72.95 & 0.00 & 65.72 & 0.00 & 23.30 & 0.01 & 12.25 & 0.27 \\
\hline 1998:Q4 & 92.06 & 0.00 & 72.95 & 0.00 & 66.14 & 0.00 & 23.10 & 0.01 & 12.17 & 0.27 \\
\hline |1999:Q1 & 92.67 & 0.00 & 3.32 & 0.00 & & 0.00 & 23.25 & 0.01 & & 0.28 \\
\hline 1999:Q2 & 94.13 & 0.00 & 35 & 0.00 & 96 & 0.00 & 22.66 & 0.01 & 11.61 & 0.31 \\
\hline 1999:Q3 & 93.44 & 0.00 & 74.80 & 0.00 & 67.20 & 0.00 & 22.26 & 0.01 & 12.18 & 0.27 \\
\hline 1999:Q4 & 94.26 & 0.00 & 5.04 & 0.00 & & 0.00 & 22.48 & 0.01 & & 0.28 \\
\hline 2000:Q1 & 94.79 & 0.00 & 7 & 0.00 & 78 & 0.00 & 22.51 & 0.01 & 34 & 0.27 \\
\hline 2000:Q2 & 95.79 & 0.00 & 76.75 & 0.00 & 68.01 & 0.00 & 22.18 & 0.02 & 14.59 & 0.15 \\
\hline 2000:Q3 & 96.82 & 0.00 & 7 & 0.00 & 13 & 0.00 & 22.12 & 0.0 & & 0.16 \\
\hline 2000:Q4 & 97.43 & 0.00 & 5 & 0.00 & 51 & 0.00 & 22.16 & 0.02 & 14.42 & 0.16 \\
\hline 2001:Q1 & 98.01 & 0.00 & 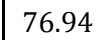 & 0.00 & 86 & 0.00 & 22.08 & 0.02 & & 0.16 \\
\hline 2001:Q2 & 98.36 & 0.00 & 7 & 0.00 & 70.12 & 0.00 & 23.30 & 0.0 & 7 & 0.14 \\
\hline 2001:Q3 & 98.67 & 0.00 & & 0.00 & & 0.00 & 23.65 & 0.01 & & 0.14 \\
\hline 2001:Q4 & 98.06 & 0.00 & & 0.00 & & 0.00 & 19 & 0.01 & & 0.15 \\
\hline 2002:Q1 & 100.98 & 0.00 & 7 & 0.00 & 69 & 0.00 & 23.48 & 0.01 & 14.48 & 0.16 \\
\hline 2002:Q2 & 100.21 & 0.00 & 6 & 0.00 & 8 & 0.00 & 22.97 & 0.01 & & 0.15 \\
\hline 2002:Q3 & 99.98 & 0.00 & 3 & 0.00 & 24 & 0.00 & 2 & 0.01 & & 0.13 \\
\hline 2002:Q4 & 99.96 & 0.00 & 7 & 0.00 & 70.69 & 0.00 & 23.19 & 0.01 & 15 & 0.12 \\
\hline 2003:Q1 & 100.29 & 0.00 & 78.8 & 0.00 & 70 & 0.00 & 23.25 & 0.0 & 16 & 0.11 \\
\hline 200 & 102.67 & 0.00 & 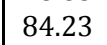 & 0.00 & 76 & 0.00 & 22 & 0.01 & 46 & 0.10 \\
\hline 2003:Q3 & 101.30 & 0.00 & & 0.00 & & 0.00 & 22.80 & 0.01 & & 0.09 \\
\hline 2003:Q4 & 100.56 & 0.00 & 8523 & 0.00 & 76.59 & 0.00 & 22.76 & 0.0 & 16.97 & 0.08 \\
\hline 2004:Q1 & 100.40 & 0.00 & 5.59 & 0.00 & 9 & 0.00 & 26.34 & 0.00 & 36 & 0.09 \\
\hline 2004:Q2 & 98.23 & 0.00 & 83.72 & 0.00 & 73.72 & 0.00 & 25.13 & 0.01 & 17.02 & 0.08 \\
\hline 2004:Q3 & 99.88 & 0.00 & 82.77 & 0.00 & 73.29 & 0.00 & 24.68 & 0.01 & 17.34 & 0.08 \\
\hline 2004:Q4 & 100.35 & 0.00 & 6 & 0.00 & 73.62 & 0.00 & 24.91 & 0.01 & 98 & 0.08 \\
\hline 2005:Q1 & 99.73 & 0.00 & 8 & 0.00 & 73.97 & 0.00 & 25.20 & 0.01 & 18.86 & 0.05 \\
\hline 2005:Q2 & 97.18 & 0.00 & 83.05 & 0.00 & 77.21 & 0.00 & 25.37 & 0.01 & 18.86 & 0.05 \\
\hline & 96.89 & & & 0.00 & & 0.00 & 26.11 & 0.00 & & 0.04 \\
\hline 2005:Q4 & 97.30 & 0.00 & 67 & 0.00 & 78.51 & 0.00 & 26.39 & 0.00 & 19.46 & 0.04 \\
\hline 2006:Q1 & 93.88 & 0.00 & 84.70 & 0.00 & 78.79 & 0.00 & 26.93 & 0.00 & 19.61 & 0.04 \\
\hline & 95.71 & 0.00 & 74.82 & 0.00 & & 0.00 & 24.41 & 0.01 & 17.23 & 0.08 \\
\hline 2006:Q3 & 94.78 & 0.00 & 74.67 & 0.00 & 70.98 & 0.00 & 24.02 & 0.01 & 17.44 & 0.08 \\
\hline 2006:Q4 & 94.20 & 0.00 & 74.96 & 0.00 & 67.51 & 0.00 & 24.18 & 0.01 & 17.78 & 0.07 \\
\hline 2007:Q1 & 92.55 & 0.00 & 66.95 & 0.00 & 65.50 & 0.00 & 23.91 & 0.01 & 17.46 & 0.08 \\
\hline 2007:Q2 & 112.23 & 0.00 & 66.85 & 0.00 & 67.21 & 0.00 & 26.53 & 0.00 & 16.70 & 0.10 \\
\hline 2007:Q3 & 114.34 & 0.00 & 94.44 & 0.00 & 67.30 & 0.00 & 27.98 & 0.00 & 17.14 & 0.09 \\
\hline 2007:Q4 & 108.26 & 0.00 & 94.60 & 0.00 & 67.63 & 0.00 & 27.83 & 0.00 & 17.16 & 0.09 \\
\hline 2008:Q1 & 99.99 & 0.00 & 90.99 & 0.00 & 79.64 & 0.00 & 24.39 & 0.01 & 17.46 & 0.08 \\
\hline 2008:Q2 & 100.75 & 0.00 & 90.71 & 0.00 & 79.58 & 0.00 & 24.35 & 0.01 & 17.55 & 0.08 \\
\hline
\end{tabular}




\begin{tabular}{|c|c|c|c|c|c|c|c|c|c|c|}
\hline \multirow[b]{2}{*}{ Vintage } & \multicolumn{2}{|c|}{ REG A: h1 } & \multicolumn{2}{|c|}{ REG A: h2 } & \multicolumn{2}{|c|}{ REG A: h3 } & \multicolumn{2}{|c|}{ REG A: h4 } & \multicolumn{2}{|c|}{ REG A: h5 } \\
\hline & LR-Stat & P-Value & LR-Stat & P-Value & LR-Stat & P-Value & LR-Stat & P-Value & LR-Stat & P-Value \\
\hline 1996:Q1 & 22.97 & 0.00 & 14.45 & 0.06 & 11.24 & 0.17 & 23.38 & 0.00 & 34.39 & 0.00 \\
\hline 1996:Q2 & 20.50 & 0.01 & 14.53 & 0.06 & 11.72 & 0.15 & 24.70 & 0.00 & 35.14 & 0.00 \\
\hline 1996:Q3 & 20.64 & 0.01 & 14.92 & 0.06 & 13.06 & 0.10 & 24.52 & 0.00 & 36.11 & 0.00 \\
\hline 1996:Q4 & 20.17 & 0.01 & 14.96 & 0.06 & 13.36 & 0.09 & 25.42 & 0.00 & 36.63 & 0.00 \\
\hline 1997:Q1 & 19.73 & 0.01 & 14.84 & 0.06 & 13.00 & 0.10 & 25.64 & 0.00 & 36.58 & 0.00 \\
\hline 1997:Q2 & 28.65 & 0.00 & 16.38 & 0.04 & 12.40 & 0.13 & 25.28 & 0.00 & 23.41 & 0.00 \\
\hline 1997:Q3 & 29.81 & 0.00 & 26.99 & 0.00 & 12.67 & 0.12 & 25.06 & 0.00 & 23.66 & 0.00 \\
\hline 1997:Q4 & 30.59 & 0.00 & 27.25 & 0.00 & 12.30 & 0.13 & 25.52 & 0.00 & 23.98 & 0.00 \\
\hline 1998:Q1 & 31.07 & 0.00 & 27.89 & 0.00 & 13.08 & 0.11 & 26.15 & 0.00 & 23.82 & 0.00 \\
\hline 1998:Q2 & 31.32 & 0.00 & 28.64 & 0.00 & 14.04 & 0.08 & 26.73 & 0.00 & 24.67 & 0.00 \\
\hline 1998:Q3 & 28.40 & 0.00 & 18.05 & 0.02 & 14.03 & 0.08 & 29.05 & 0.00 & 27.15 & 0.00 \\
\hline 1998:Q4 & 29.21 & 0.00 & 31.38 & 0.00 & 14.49 & 0.07 & 29.97 & 0.00 & 28.27 & 0.00 \\
\hline 1999:Q1 & 29.52 & 0.00 & 31.51 & 0.00 & 14.47 & 0.07 & 30.64 & 0.00 & 29.04 & 0.00 \\
\hline 1999:Q2 & 30.01 & 0.00 & 31.69 & 0.00 & 14.29 & 0.08 & 31.52 & 0.00 & 29.64 & 0.00 \\
\hline 1999:Q3 & 28.96 & 0.00 & 30.26 & 0.00 & 13.48 & 0.10 & 28.35 & 0.00 & 29.37 & 0.00 \\
\hline 1999:Q4 & 10.65 & 0.24 & 7.40 & 0.52 & 10.23 & 0.26 & 10.83 & 0.22 & 22.12 & 0.00 \\
\hline 2000:Q1 & 74.49 & 0.00 & 45.04 & 0.00 & 67.96 & 0.00 & 57.99 & 0.00 & 87.88 & 0.00 \\
\hline 2000:Q2 & 23.19 & 0.00 & 12.25 & 0.16 & 16.00 & 0.05 & 20.95 & 0.01 & 25.18 & 0.00 \\
\hline 2000:Q3 & 23.58 & 0.00 & 11.95 & 0.17 & 13.37 & 0.11 & 19.55 & 0.01 & 25.48 & 0.00 \\
\hline 2000:Q4 & 24.53 & 0.00 & 11.86 & 0.18 & 12.91 & 0.13 & 19.69 & 0.01 & 25.76 & 0.00 \\
\hline 2001:Q1 & 25.47 & 0.00 & 11.94 & 0.18 & 13.06 & 0.13 & 19.78 & 0.01 & 26.26 & 0.00 \\
\hline 2001:Q2 & 25.59 & 0.00 & 13.21 & 0.12 & 11.94 & 0.18 & 19.58 & 0.01 & 22.71 & 0.00 \\
\hline 2001:Q3 & 25.56 & 0.00 & 13.49 & 0.12 & 13.35 & 0.12 & 18.21 & 0.02 & 24.32 & 0.00 \\
\hline 2001:Q4 & 22.80 & 0.00 & 11.70 & 0.19 & 14.67 & 0.08 & 21.03 & 0.01 & 25.87 & 0.00 \\
\hline 2002:Q1 & 22.69 & 0.01 & 12.06 & 0.18 & 14.95 & 0.07 & 21.85 & 0.01 & 26.23 & 0.00 \\
\hline 2002:Q2 & 16.93 & 0.04 & 12.10 & 0.18 & 16.06 & 0.05 & 24.09 & 0.00 & 26.84 & 0.00 \\
\hline 2002:Q3 & 34.10 & 0.00 & 18.55 & 0.02 & 14.12 & 0.10 & 22.13 & 0.01 & 25.26 & 0.00 \\
\hline 2002:Q4 & 33.55 & 0.00 & 18.41 & 0.02 & 12.19 & 0.17 & 20.59 & 0.01 & 25.41 & 0.00 \\
\hline 2003:Q1 & 33.61 & 0.00 & 18.48 & 0.02 & 20.84 & 0.01 & 21.01 & 0.01 & 25.68 & 0.00 \\
\hline 2003:Q2 & 33.64 & 0.00 & 18.54 & 0.02 & 19.88 & 0.01 & 21.07 & 0.01 & 24.19 & 0.00 \\
\hline 2003:Q3 & 34.03 & 0.00 & 19.03 & 0.02 & 20.96 & 0.01 & 21.42 & 0.01 & 24.56 & 0.00 \\
\hline 2003:Q4 & 32.57 & 0.00 & 21.69 & 0.01 & 21.46 & 0.01 & 18.06 & 0.03 & 24.68 & 0.00 \\
\hline 2004:Q1 & 61.90 & 0.00 & 26.79 & 0.00 & 29.51 & 0.00 & 30.44 & 0.00 & 22.82 & 0.00 \\
\hline 2004:Q2 & 61.00 & 0.00 & 27.76 & 0.00 & 31.25 & 0.00 & 28.41 & 0.00 & 23.13 & 0.00 \\
\hline 2004:Q3 & 56.62 & 0.00 & 25.84 & 0.00 & 29.59 & 0.00 & 26.55 & 0.00 & 21.98 & 0.01 \\
\hline 2004:Q4 & 57.86 & 0.00 & 25.85 & 0.00 & 29.90 & 0.00 & 26.72 & 0.00 & 22.27 & 0.01 \\
\hline 2005:Q1 & 57.44 & 0.00 & 26.67 & 0.00 & 29.97 & 0.00 & 24.76 & 0.00 & 28.93 & 0.00 \\
\hline 2005:Q2 & 57.83 & 0.00 & 24.28 & 0.00 & 29.88 & 0.00 & 24.79 & 0.00 & 27.62 & 0.00 \\
\hline 2005:Q3 & 56.79 & 0.00 & 21.42 & 0.01 & 28.67 & 0.00 & 22.72 & 0.01 & 27.50 & 0.00 \\
\hline 2005:Q4 & 56.20 & 0.00 & 21.70 & 0.01 & 28.24 & 0.00 & 21.59 & 0.01 & 26.26 & 0.00 \\
\hline 2006:Q1 & 58.77 & 0.00 & 22.54 & 0.01 & 28.51 & 0.00 & 21.75 & 0.01 & 26.51 & 0.00 \\
\hline 2006:Q2 & 60.04 & 0.00 & 23.57 & 0.00 & 28.47 & 0.00 & 22.37 & 0.01 & 25.28 & 0.00 \\
\hline 2006:Q3 & 55.76 & 0.00 & 22.46 & 0.01 & 24.07 & 0.00 & 19.70 & 0.02 & 21.66 & 0.01 \\
\hline 2006:Q4 & 54.97 & 0.00 & 22.76 & 0.01 & 25.06 & 0.00 & 19.81 & 0.02 & 22.02 & 0.01 \\
\hline 2007:Q1 & 48.78 & 0.00 & 22.96 & 0.01 & 26.91 & 0.00 & 19.08 & 0.02 & 22.50 & 0.01 \\
\hline 2007:Q2 & 65.51 & 0.00 & 22.21 & 0.01 & 27.04 & 0.00 & 19.39 & 0.02 & 21.49 & 0.01 \\
\hline 2007:Q3 & 75.51 & 0.00 & 52.68 & 0.00 & 29.53 & 0.00 & 18.04 & 0.03 & 21.61 & 0.01 \\
\hline 2007:Q4 & 76.62 & 0.00 & 53.37 & 0.00 & 29.60 & 0.00 & 18.21 & 0.03 & 21.82 & 0.01 \\
\hline 2008:Q1 & 76.87 & 0.00 & 60.45 & 0.00 & 58.68 & 0.00 & 18.00 & 0.03 & 23.27 & 0.01 \\
\hline 2008:Q2 & 76.17 & 0.00 & 61.38 & 0.00 & 58.07 & 0.00 & 18.45 & 0.03 & 22.42 & 0.01 \\
\hline
\end{tabular}




\begin{tabular}{|c|c|c|c|c|c|c|c|c|c|c|}
\hline \multirow[b]{3}{*}{ Vintage } & \multirow{2}{*}{\multicolumn{2}{|c|}{ REG B: h1 }} & \multirow{2}{*}{\multicolumn{2}{|c|}{ REG B: h2 }} & \multirow{2}{*}{\multicolumn{2}{|c|}{ REG B: h3 }} & \multirow{2}{*}{\multicolumn{2}{|c|}{ REG B: h4 }} & \multirow{2}{*}{\multicolumn{2}{|c|}{ REG B: h5 }} \\
\hline & & & & & & & & & & \\
\hline & LR-Stat & P-Value & LR-Stat & P-Value & LR-Stat & P-Value & LR-Stat & P-Value & LR-Stat & P-Value \\
\hline \begin{tabular}{|l|}
$1996: Q 1$ \\
\end{tabular} & 53.39 & 0.00 & 22.95 & 0.00 & 18.71 & 0.01 & 17.24 & 0.02 & 18.03 & 0.01 \\
\hline 1996:Q2 & 53.46 & 0.00 & 22.98 & 0.00 & 18.94 & 0.01 & 17.09 & 0.02 & 18.08 & 0.01 \\
\hline 1996:Q3 & 53.91 & 0.00 & 22.54 & 0.00 & 19.03 & 0.01 & 16.90 & 0.03 & 17.48 & 0.02 \\
\hline 1996:Q4 & 54.66 & 0.00 & 22.85 & 0.00 & 19.58 & 0.01 & 17.34 & 0.02 & 17.70 & 0.02 \\
\hline 1997:Q1 & 54.50 & 0.00 & 21.12 & 0.01 & 19.54 & 0.01 & 17.47 & 0.02 & 17.64 & 0.02 \\
\hline 1997:Q2 & 56.44 & 0.00 & 19.67 & 0.01 & 20.19 & 0.01 & 17.04 & 0.03 & 18.13 & 0.02 \\
\hline 1997:Q3 & 56.91 & 0.00 & 20.68 & 0.01 & 20.86 & 0.01 & 17.18 & 0.02 & 19.26 & 0.01 \\
\hline 1997:Q4 & 56.80 & 0.00 & 20.95 & 0.01 & 21.19 & 0.01 & 17.27 & 0.02 & 20.75 & 0.01 \\
\hline 1998:Q1 & 57.89 & 0.00 & 21.49 & 0.01 & 21.51 & 0.01 & 17.45 & 0.02 & 21.08 & 0.01 \\
\hline 1998:Q2 & 57.97 & 0.00 & 23.98 & 0.00 & 21.49 & 0.01 & 19.65 & 0.01 & 22.08 & 0.00 \\
\hline 1998:Q3 & 47.46 & 0.00 & 24.34 & 0.00 & 21.92 & 0.01 & 19.22 & 0.01 & 22.91 & 0.00 \\
\hline 1998:Q4 & 48.32 & 0.00 & 24.62 & 0.00 & 22.20 & 0.00 & 19.49 & 0.01 & 23.64 & 0.00 \\
\hline 1999:Q1 & 49.23 & 0.00 & 25.04 & 0.00 & 22.51 & 0.00 & 20.04 & 0.01 & 24.43 & 0.00 \\
\hline 1999:Q2 & 61.57 & 0.00 & 26.17 & 0.00 & 23.81 & 0.00 & 20.52 & 0.01 & 26.82 & 0.00 \\
\hline 1999:Q3 & 57.98 & 0.00 & 25.49 & 0.00 & 23.23 & 0.00 & 18.59 & 0.02 & 33.13 & 0.00 \\
\hline 1999:Q4 & 58.34 & 0.00 & 25.28 & 0.00 & 23.56 & 0.00 & 17.99 & 0.02 & 32.89 & 0.00 \\
\hline 2000:Q1 & 59.08 & 0.00 & 25.35 & 0.00 & 23.51 & 0.00 & 17.84 & 0.02 & 32.71 & 0.00 \\
\hline 2000:Q2 & 59.81 & 0.00 & 22.25 & 0.01 & 21.69 & 0.01 & 17.02 & 0.03 & 31.51 & 0.00 \\
\hline 2000:Q3 & 59.99 & 0.00 & 20.70 & 0.01 & 18.23 & 0.02 & 16.19 & 0.04 & 30.07 & 0.00 \\
\hline 2000:Q4 & 61.86 & 0.00 & 21.09 & 0.01 & 18.55 & 0.02 & 16.25 & 0.04 & 28.31 & 0.00 \\
\hline 2001:Q1 & 61.98 & 0.00 & 20.46 & 0.01 & 18.24 & 0.02 & 15.88 & 0.05 & 27.79 & 0.00 \\
\hline 2001:Q2 & 59.61 & 0.00 & 20.81 & 0.01 & 16.56 & 0.04 & 15.55 & 0.06 & 25.22 & 0.00 \\
\hline 2001:Q3 & 60.34 & 0.00 & 20.55 & 0.01 & 16.87 & 0.04 & 13.44 & 0.11 & 25.12 & 0.00 \\
\hline 2001:Q4 & 56.90 & 0.00 & 19.30 & 0.02 & 17.40 & 0.03 & 14.27 & 0.09 & 26.26 & 0.00 \\
\hline 2002:Q1 & 62.14 & 0.00 & 18.82 & 0.02 & 16.97 & 0.04 & 16.37 & 0.04 & 28.11 & 0.00 \\
\hline 2002:Q2 & 63.69 & 0.00 & 21.49 & 0.01 & 19.27 & 0.02 & 20.13 & 0.01 & 32.86 & 0.00 \\
\hline 2002:Q3 & 63.47 & 0.00 & 20.75 & 0.01 & 19.03 & 0.02 & 19.32 & 0.02 & 30.88 & 0.00 \\
\hline 2002:Q4 & 63.68 & 0.00 & 21.18 & 0.01 & 19.29 & 0.02 & 19.81 & 0.01 & 31.33 & 0.00 \\
\hline 2003:Q1 & 63.96 & 0.00 & 21.38 & 0.01 & 18.59 & 0.02 & 20.06 & 0.01 & 31.49 & 0.00 \\
\hline 2003:Q2 & 68.53 & 0.00 & 22.92 & 0.01 & 22.38 & 0.01 & 18.69 & 0.02 & 35.32 & 0.00 \\
\hline 2003:Q3 & 69.85 & 0.00 & 23.64 & 0.00 & 22.20 & 0.01 & 19.90 & 0.01 & 36.15 & 0.00 \\
\hline 2003:Q4 & 67.36 & 0.00 & 23.63 & 0.00 & 22.14 & 0.01 & 20.13 & 0.01 & 36.51 & 0.00 \\
\hline 2004:Q1 & 67.08 & 0.00 & 23.57 & 0.00 & 22.73 & 0.01 & 24.99 & 0.00 & 36.70 & 0.00 \\
\hline 2004:Q2 & 61.08 & 0.00 & 21.47 & 0.01 & 23.63 & 0.00 & 23.23 & 0.00 & 34.82 & 0.00 \\
\hline 2004:Q3 & 61.69 & 0.00 & 19.27 & 0.02 & 21.37 & 0.01 & 23.19 & 0.00 & 32.71 & 0.00 \\
\hline 2004:Q4 & 61.82 & 0.00 & 18.66 & 0.03 & 21.42 & 0.01 & 23.64 & 0.00 & 32.11 & 0.00 \\
\hline 2005:Q1 & 61.31 & 0.00 & 17.90 & 0.03 & 21.44 & 0.01 & 22.68 & 0.01 & 34.87 & 0.00 \\
\hline 2005:Q2 & 58.37 & 0.00 & 19.51 & 0.02 & 24.24 & 0.00 & 22.46 & 0.01 & 35.81 & 0.00 \\
\hline 2005:Q3 & 58.28 & 0.00 & 20.22 & 0.02 & 23.22 & 0.01 & 22.49 & 0.01 & 37.01 & 0.00 \\
\hline 2005:Q4 & 50.72 & 0.00 & 19.85 & 0.02 & 23.24 & 0.01 & 19.76 & 0.02 & 33.01 & 0.00 \\
\hline 2006:Q1 & 53.22 & 0.00 & 18.84 & 0.03 & 22.80 & 0.01 & 19.85 & 0.02 & 33.31 & 0.00 \\
\hline 2006:Q2 & 61.43 & 0.00 & 19.50 & 0.02 & 18.98 & 0.02 & 16.95 & 0.04 & 29.00 & 0.00 \\
\hline 2006:Q3 & 59.10 & 0.00 & 18.69 & 0.03 & 18.50 & 0.03 & 16.49 & 0.05 & 23.63 & 0.00 \\
\hline 2006:Q4 & 57.83 & 0.00 & 18.77 & 0.03 & 19.75 & 0.02 & 16.23 & 0.06 & 23.22 & 0.00 \\
\hline 2007:Q1 & 49.27 & 0.00 & 12.42 & 0.19 & 20.11 & 0.02 & 16.46 & 0.05 & 23.29 & 0.00 \\
\hline 2007:Q2 & 60.63 & 0.00 & 11.86 & 0.22 & 19.57 & 0.02 & 14.60 & 0.10 & 23.42 & 0.00 \\
\hline 2007:Q3 & 62.22 & 0.00 & 27.45 & 0.00 & 20.23 & 0.02 & 14.54 & 0.10 & 24.79 & 0.00 \\
\hline 2007:Q4 & 64.23 & 0.00 & 28.22 & 0.00 & 20.21 & 0.02 & 14.77 & 0.09 & 25.19 & 0.00 \\
\hline 2008:Q1 & 64.02 & 0.00 & 30.84 & 0.00 & 22.57 & 0.01 & 15.92 & 0.07 & 29.76 & 0.00 \\
\hline 2008:Q2 & 64.43 & 0.00 & 28.47 & 0.00 & 21.73 & 0.01 & 15.74 & 0.07 & 27.79 & 0.00 \\
\hline
\end{tabular}

